\title{
THERMAL PERFORMANCE ANALYSIS FOR WSB DRUM
}

\author{
Si Young Lee
}

May 2008

Washington Savannah River Company Savannah River National Laboratory Aiken, SC 29808

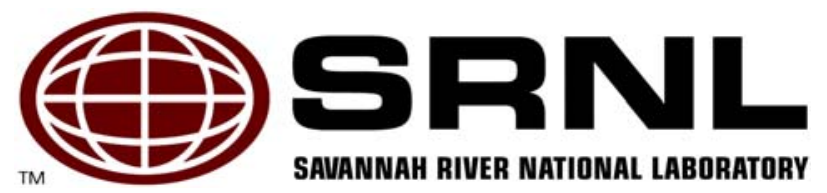




\section{DISCLAIMER}

This report was prepared by Washington Savannah River Company (WSRC) for the United States Department of Energy under Contract No. DE-AC09-96SR18500 and is an account of work performed under that contract. Neither the United States Department of Energy, nor WSRC, nor any of their employees makes any warranty, expressed or implied, or assumes any legal liability or responsibility for the accuracy, completeness, or usefulness, of any information, apparatus, or product or process disclosed herein or represents that its use will not infringe privately owned rights. Reference herein to any specific commercial product, process, or service by trademark, name, manufacturer or otherwise does not necessarily constitute or imply endorsement, recommendation, or favoring of same by WSRC or by the United States Government or any agency thereof. The views and opinions of the authors expressed herein do not necessarily state or reflect those of the United States Government or any agency thereof.

\section{Printed in the United States of America}

Prepared For

\section{U.S. Department of Energy}


Keywords: Heat Transfer Calculations, Natural Convection, WSB Drum,

Thermal Performance, 55-Gallon Drum

\title{
THERMAL PERFORMANCE ANALYSIS FOR WSB DRUM
}

\author{
Si Young Lee
}

May 2008

Washington Savannah River Company Savannah River National Laboratory Aiken, SC 29808

Prepared for the U.S. Department of Energy Under Contract No. DE-AC09-96SR18500 


\section{Review and Approvals}

S. Y. Lee, Author

Date

Eng. Modeling and Simulation Group, SRNL

F. G. Smith, III, Technical Reviewer

Date

Eng. Modeling and Simulation Group, SRNL

A. D. Cozzi, Customer Reviewer

Date

Stabilization Science Research Group, SRNL

S. J. Hensel, Manager

Date

Eng. Modeling and Simulation Group, SRNL

D. A. Crowley, Manager

Date

Stabilization Science Research Group, SRNL 


\section{Table of Contents}

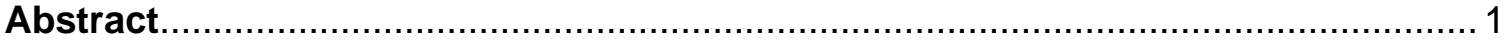

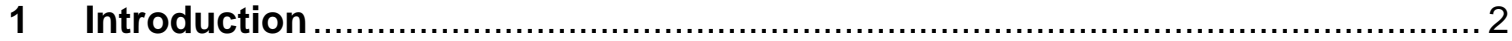

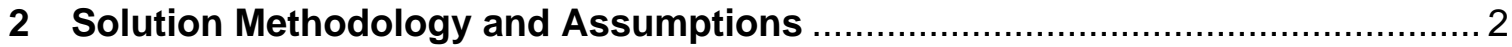

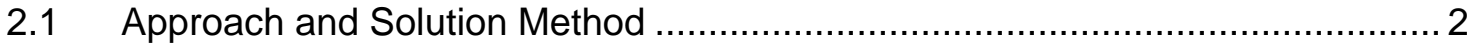

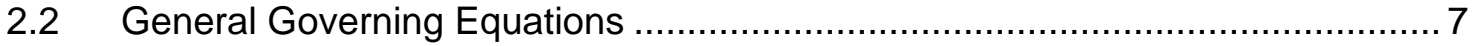

2.3 Modeling Assumptions and Design Parameters ...................................... 12

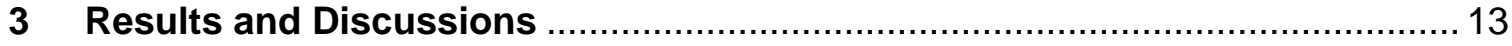

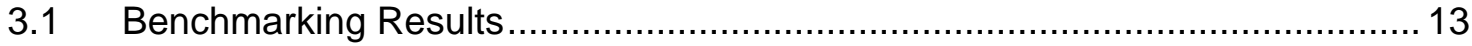

3.1.1 Transient Conduction Response to Sudden Cooling ............................. 14

3.1.2 Natural Convection inside a Rectangular Enclosure ............................ 17

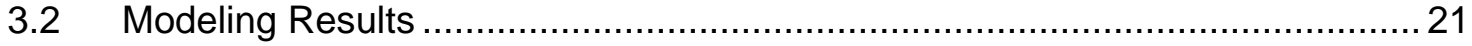

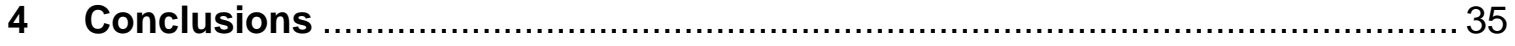

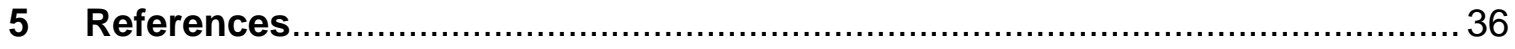

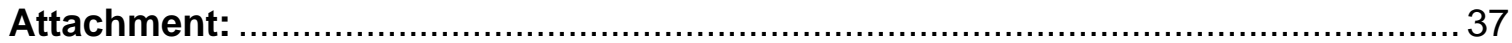




\section{List of Figures}

Figure 1. Modeling geometry and computational domain for the present analysis ......... 4

Figure 2. Heat source per unit mass as function of time ......................................... 4

Figure 3. Axisymmetric two-dimensional computational domain used for the present

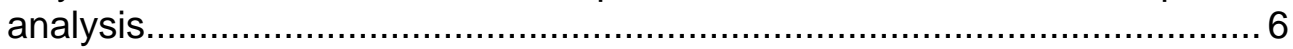

Figure 4. Heat transfer coefficients at the wall surface of the 55-gallon drum for the

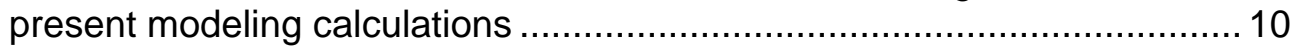

Figure 5. Two-dimensional meshes for the computational domain used for the present analysis..................................................................................... 12

Figure 6. Infinite slab plate subjected to sudden cooling of surfaces ........................ 14

Figure 7. Benchmarking results of the present model against the theoretical calculations for the spatial temperature distributions across the slab at 10 seconds of transient time 16

Figure 8. Benchmarking results of the present model against the theoretical calculations for the transient thermal response.

Figure 9. Natural convection driven by the temperature gradient between two different wall temperatures inside a rectangular slit enclosure.

Figure 10. Comparison of the modeling predictions with theoretical results for the two different temperature differences between the two plates as shown in Fig. 8.

Figure 11. Transient maximum drum surface temperature and maximum waste temperature for $65 \%$-filled heat source provided by Fig. 2 (Initial waste temperature $=43^{\circ} \mathrm{C}$ and ambient temperature $=27^{\circ} \mathrm{C}$, and steady state temperatures based on the heat source averaged over the 70 -hour period)

Figure 12. Transient drum surface temperature distributions for $65 \%$-filled heat source provided by Fig. 2 (Initial waste temperature $=43^{\circ} \mathrm{C}$ and ambient temperature $=27^{\circ} \mathrm{C}$, and steady state temperatures based on the heat source averaged over the 70 -hour period).

Figure 13. Temperature contour plot at 32 hours after initial conditions with initial waste temperature $=43^{\circ} \mathrm{C}$ and ambient temperature $=27^{\circ} \mathrm{C}(65 \%$-filled drum) $\ldots 26$

Figure 14. Density distributions for the enclosed gas regions inside the drum at 32 hours for initial waste temperature $=43^{\circ} \mathrm{C}$ and ambient temperature $=27^{\circ} \mathrm{C}$ under the baseline drum (65\%-filled drum).

Figure 15. Air flow patterns driven by temperature gradient inside the vapor space above the cement at 32 hours after initial conditions with initial waste temperature $=43^{\circ} \mathrm{C}$ and ambient temperature $=27^{\circ} \mathrm{C}(65 \%$-filled drum $) \ldots 28$

Figure 16. Transient snapshots of temperature distributions across the central plane of the 55-gallon drum with $65 \%$-filled waste form for initial waste temperature $=43^{\circ} \mathrm{C}$ and ambient temperature $=27^{\circ} \mathrm{C}$ (As color code, red color is indicated as $95.46^{\circ} \mathrm{C}$, blue one is $26.85^{\circ} \mathrm{C}$ ). 


\section{WSRC-STI-2008-00262}

Figure 17. Transient snapshots of flow patterns for the enclosed gas region above the top surface of the cemented waste form inside the 55-gallon drum with $65 \%$-filled waste form for initial waste temperature $=43^{\circ} \mathrm{C}$ and ambient temperature $=27^{\circ} \mathrm{C}$ (As color code, red color is indicated as $0.338 \mathrm{~m} / \mathrm{sec}$, blue one is $0 \mathrm{~m} / \mathrm{sec}$ ). 30

Figure 18. Comparison of transient maximum drum surface and waste temperatures between two different initial waste temperatures for the transient heat source provided by Fig. 2 .

Figure 19. Comparisons of transient maximum drum surface and cement waste temperatures for different loadings of cement waste in a drum container (Initial waste temperature $=43^{\circ} \mathrm{C}$ and ambient temperature $=27^{\circ} \mathrm{C}$ ).

Figure 20. Comparison of temperature distributions cooled by natural convection at 32hour transient time for different sizes of gas enclosures above the top surface of the waste form cement region due to the different loading volumes of the cement waste form (As color code, red has temperature higher than $96.0^{\circ} \mathrm{C}$, and blue one has $26.85^{\circ} \mathrm{C}$.) 32

Figure 21. Comparison of gas velocity flow patterns driven by natural convection at 32hour transient time for different sizes of gas enclosures above the top surface of the waste form cement region due to the different loading volume of the cement waste form (As color code, red has velocity higher than 0.39 $\mathrm{m} / \mathrm{sec}$, and blue one has zero velocity.) 33 


\section{List of Tables}

Table 1. Baseline design and operating conditions of 55-gallon drum used for the present study.....

Table 2. All the cases for the thermal analysis of the 55-gallon WSB drum package ........ 7

Table 3. Material and thermal properties for the analysis ....................................... 7

Table 4. Material and thermal properties used for the benchmarking analysis................. 15

Table 5. Quantitative comparison of the modeling predictions with the theoretical results15

Table 6. Comparison of maximum natural convective velocities driven by temperature gradients between theoretical results and modeling predictions.......................20

Table 7. Transient maximum cement and drum surface temperatures for three different

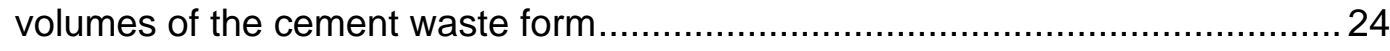

Table 8. Comparison of convection to conduction cooling ratios for different height $(H)$ of the air enclosure above the cement waste form with the same heat loading at 32 hours of transient time during WSB drum storage ..................................... 34

Table 9. Maximum surface and cement temperatures during the transient period of drum storage in a WSB facility 


\section{Abstract}

The Nuclear Nonproliferation Programs Design Authority is in the design stage of the Waste Solidification Building (WSB) for the treatment and solidification of the radioactive liquid waste streams generated by the Pit Disassembly and Conversion Facility (PDCF) and Mixed Oxide (MOX) Fuel Fabrication Facility (MFFF). The waste streams will be mixed with a cementitious dry mix in a 55-gallon waste container. Savannah River National Laboratory (SRNL) has been performing the testing and evaluations to support technical decisions for the WSB. Engineering Modeling \& Simulation Group was requested to evaluate the thermal performance of the 55-gallon drum containing hydration heat source associated with the current baseline cement waste form.

A transient axi-symmetric heat transfer model for the drum partially filled with waste form cement has been developed and heat transfer calculations performed for the baseline design configurations. For this case, 65 percent of the drum volume was assumed to be filled with the waste form, which has transient hydration heat source, as one of the baseline conditions. A series of modeling calculations has been performed using a computational heat transfer approach.

The baseline modeling results show that the time to reach the maximum temperature of the 65 percent filled drum is about 32 hours when a $43^{\circ} \mathrm{C}$ initial cement temperature is assumed to be cooled by natural convection with $27^{\circ} \mathrm{C}$ external air. In addition, the results computed by the present model were compared with analytical solutions. The modeling results will be benchmarked against the prototypic test results. The verified model will be used for the evaluation of the thermal performance for the WSB drum. 


\section{Introduction}

The Nuclear Nonproliferation Programs Design Authority is in the design stage of the Waste Solidification Building (WSB) for the treatment and solidification of radioactive liquid waste streams generated by the Pit Disassembly and Conversion Facility (PDCF) and Mixed Oxide (MOX) Fuel Fabrication Facility (MFFF). The waste streams will be mixed with a cementitious dry mix in a 55-gallon waste container. The container will be a cylindrical stainless steel drum with 22.5 in diameter and 33 in tall [See Attachment]. Under the current formulation, the drum will be filled with cement waste form up to maximum 75 percent. The Savannah River National Laboratory (SRNL) has been requested to perform full-scale drum tests and modeling evaluations to support technical decision for the WSB [1]. Recently, SRNL prepared a sample of the baseline HighActivity Waste (HAW) form and measured the heat of hydration associated with the cement waste form [2].

The primary objective of this work is to develop a heat transfer model for the 55-gallon WSB drum partially filled with the cement and to evaluate the thermal performance of the drum package containing hydration heat source associated with the current baseline cement waste form. The modeling results will be benchmarked against the prototypic test results. The verified model will be used as an evaluation tool for the thermal performance of the WSB drum.

\section{Solution Methodology and Assumptions}

For the evaluation of thermal performance of the WSB drum package, the baseline design involves a 55-gallon drum with dimensions of 33 in. tall and 22.5 in. diameter, which is filled with cement waste form by 65 percentages of the drum volume. The drum container will be filled with the cement up to $75 \%$ drum volume. Geometrical configurations and dimensions for the present analysis are shown in Fig. 1. The cement region has transient heat source associated with the hydration of the cemented waste mixture. Figure 2 presents the measured heat loading per unit mass of the cement waste. In the figure it is also compared with the polynomially-fit curve obtained by using a least-square method. Average heat source density over 70-hour transient period of the cement waste form is about $0.373 \mathrm{~W} / \mathrm{kg}$. When the drum is filled with the cement waste by 65 vol\%, total heat loading of the WSB drum corresponding to the average heat source density is about 115 watts during the 70 -hour transient period. It corresponds to about $3.1 \mathrm{~W} /$ gallon of volumetric heat source.

\subsection{Approach and Solution Method}

For the thermal performance analysis of the drum package, this heat loading will be assumed to be cooled through a coupled conduction and natural convection heat transfer mechanism under the baseline operating conditions. Detailed modeling conditions used for the baseline analysis are provided in Table 1.

In the case of handling the WSB drum, there are concerns about the transient thermal response rates and the maximum transient temperatures reached for partially-loaded drums containing the hydration heat source. Fast thermal response and high peak temperature can lead to unacceptable consequences such as cement degradation and 
solution boiling. For computational modeling purposes, a conservative approach was taken by assuming that the primary cooling mechanism of the drum was a coupled heat transfer process of conduction and natural convection, and that radiative heat removal from the top surface of the cement waste form inside the drum was negligible since maximum temperatures under the nominal operating conditions are expected to be lower than $100^{\circ} \mathrm{C}$.

The prototypic modeling geometry was created using a body-fitted coordinate system and structured multi-block grids in the Computational Fluid Dynamics (CFD) preprocessing environment as shown Fig 3. An axi-symmetric two-dimensional transient heat transfer model coupled with convective momentum driven by temperature gradient across the boundary layer was developed to assess the thermal performance of the WSB drum partially filled with the cement waste form containing heat source under the prototypic geometry as shown in Fig. 1.

The drum configuration shown in Fig. 1 involving the enclosed air region above the 65\%filled cement waste region will serve as the initial and baseline configuration. Alternative configurations involving two different cement fill volume percentages such as $50 \%$ and $75 \%$ will be also evaluated for sensitivity analysis. The measure data for the hydration heat source $q$ as described in the previous work [2] was polynomially fitted by a least square method.

$q=A+B t+C t^{2}+D t^{3}+E t^{4}+F t^{5}+G t^{6}+H t^{7}+I t^{8}+J t^{9}$

In Eq. (1) $q$ is transient heat source per unit the waste mass in W/kg and $t$ is transient time in hour.

The coefficients in eq. (1) are as follows:

$$
\begin{aligned}
& A=8.3381 \times 10^{-2} \\
& B=2.0446 \times 10^{-2} \\
& C=-3.2615 \times 10^{-3} \\
& D=1.5252 \times 10^{-3} \\
& E=-1.5239 \times 10^{-4} \\
& F=6.8647 \times 10^{-6} \\
& G=-1.6763 \times 10^{-7} \\
& H=2.3068 \times 10^{-9} \\
& I=-1.6873 \times 10^{-11} \\
& J=5.1118 \times 10^{-14}
\end{aligned}
$$




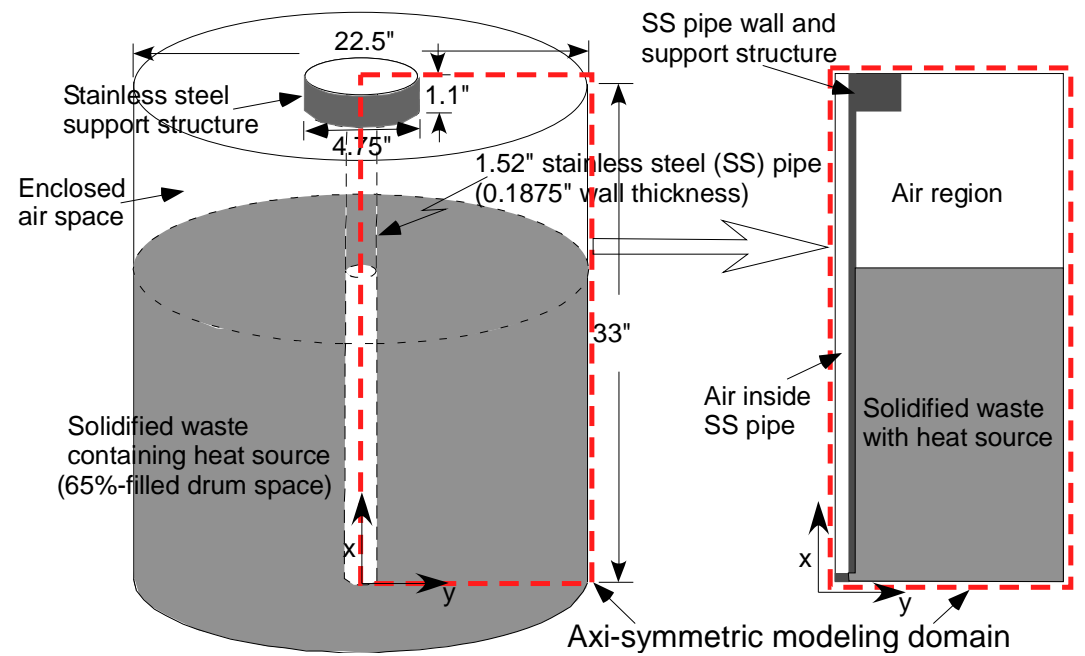

Figure 1. Modeling geometry and computational domain for the present analysis

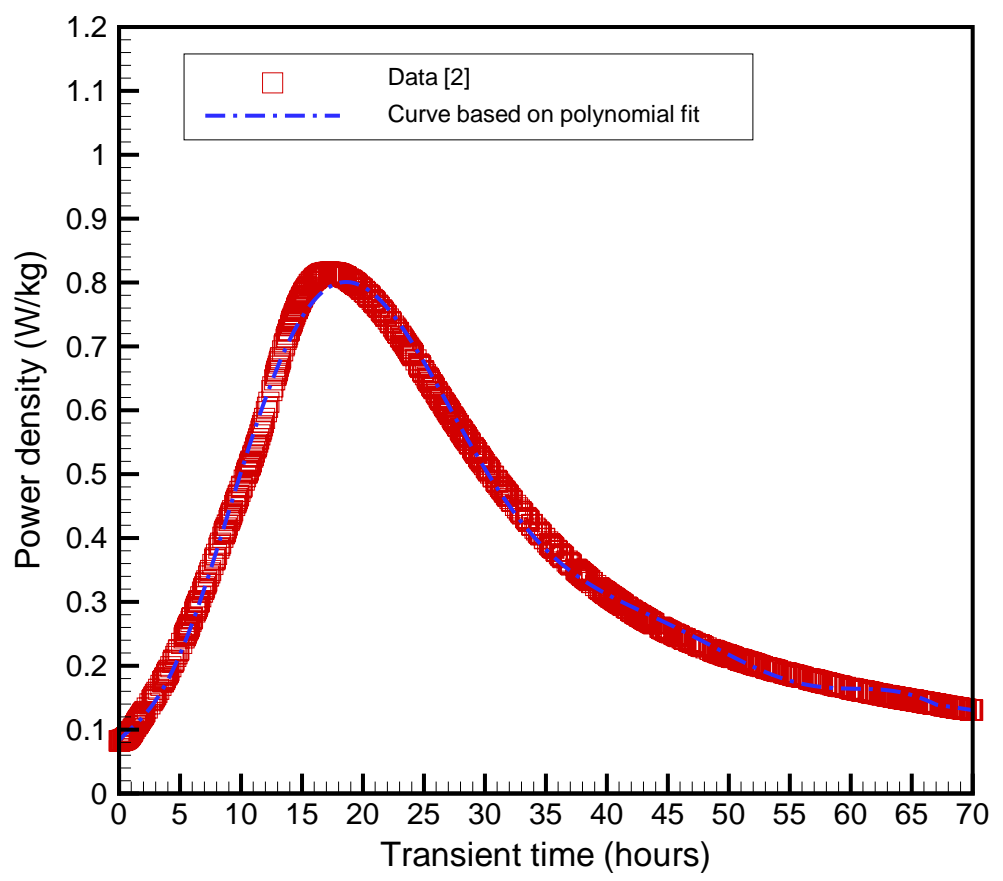

Figure 2. Heat source per unit mass as function of time 
Table 1. Baseline design and operating conditions of 55-gallon drum used for the present study.

\begin{tabular}{|c|c|c|}
\hline \multicolumn{2}{|c|}{ Parameters } & Modeling conditions \\
\hline \multirow{2}{*}{$\begin{array}{l}\text { Drum } \\
\text { dimensions }\end{array}$} & Diameter & 22.5 in \\
\hline & Height & 33 in \\
\hline \multicolumn{2}{|c|}{ Drum configurations } & See Fig. 1 \\
\hline \multicolumn{2}{|c|}{$\begin{array}{l}\text { Level of cement waste form inside } \\
55 \text {-gallon drum }\end{array}$} & $\begin{array}{c}\left.16.6 \text { in }(50 \% \text {-filled })^{+}, 21.45 \text { in (65\%-filled }\right)^{\star} \\
\text { and } 24.75 \text { in }(75 \% \text {-filled })^{+}\end{array}$ \\
\hline \multicolumn{2}{|c|}{ Initial temperature of cement waste form } & $26.85^{\circ} \mathrm{C}^{+}, 43^{\circ} \mathrm{C}^{*}$ \\
\hline \multicolumn{2}{|c|}{ Ambient temperature } & $26.85^{\circ} \mathrm{C}$ \\
\hline \multicolumn{2}{|c|}{$\begin{array}{l}\text { Heat source averaged over the } 70 \text {-hour } \\
\text { transient period }\end{array}$} & $\begin{array}{l}0.373^{\star *} \mathrm{~W} / \mathrm{kg} \text { (Transient heat source due to } \\
\text { cement hydration as shown in Fig. } 2[2] \text { ) }\end{array}$ \\
\hline
\end{tabular}

Note: * Baseline operating conditions

+ For the sensitivity analysis

** Computed by $\left(q^{\prime \prime \prime}\right)_{\text {avg }}=\int_{t=0}^{t=70 \text { hrs }} q^{\prime \prime \prime}(t) d t$

The model considers three basic cases as shown in Table 2. The first case, Case 1, is assumed to have 65\%-filled drum package and involve internal heat transfer by conduction for the cement waste form and by a coupled mechanism of conduction and convection for the enclosed air region above the cement region. Heat transfer at the walls involves natural convection from the external wall boundary to the ambient air, with the assumption that the air serves as an infinite heat sink at constant temperature as shown in Table 1. Cases 2 and 3 shown in Table 2 are the WSB drum packages filled with $75 \%$ and $50 \%$, respectively. All three cases are assumed to have the same volumetric heat load under the same initial and boundary conditions as provided in Table 1. In this case, it is assumed there is no heat loss at the bottom wall boundary of the drum (adiabatic boundary) and all heat transfer through the other wall surfaces to the ambient is via natural convection. Heat transfer analysis of the drum package for the basic cases is performed for a given boundary condition by using a computational heat transfer approach on a Cartesian $\mathrm{x}-\mathrm{y}$ grid with a commercial CFD code, Fluent ${ }^{\mathrm{TM}}$ [3], environment.

For heat transfer analysis, the actual baseline drum design involves a cement waste region with 21.45 in high, resulting in a 11.55 in height for the enclosed air region. This height is believed to have an impact of natural convective cooling on the coolability of the WSB drum package. The drum design is annular due to the presence of a center pipe with an outside diameter of 1.52 in. The center pipe will be filled with air. At the top of the pipe there is a sintered metal filter to release hydrogen generated in the cementation process of the waste streams. 
Page: $\quad 6$ of 38

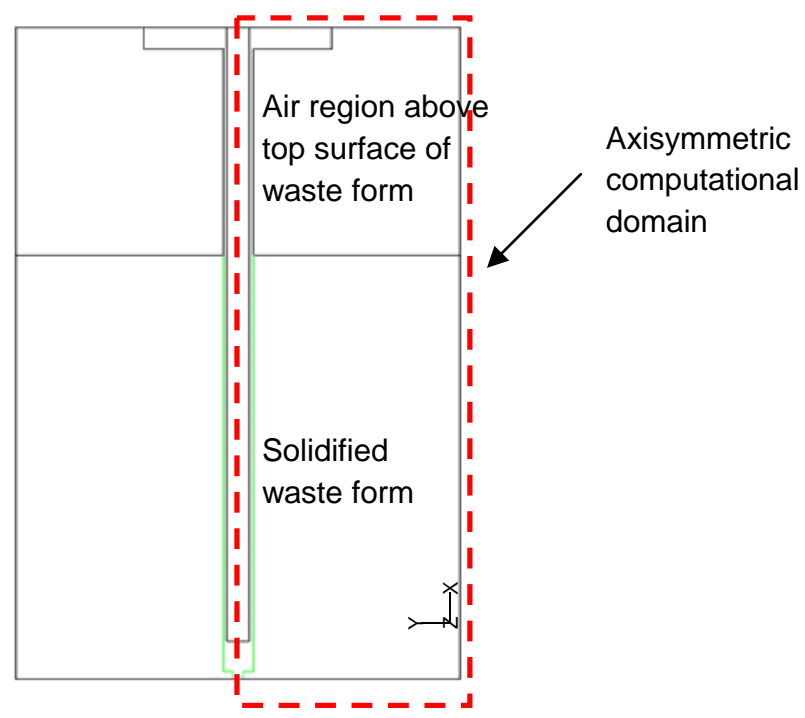

Figure 3. Axisymmetric two-dimensional computational domain used for the present analysis

The density of the mixture was calculated from the baseline HAW waste form formulation as a simple weighted average of the simulated waste solution densities based on the weight fraction. The bulk density for the cement waste form is $2200 \mathrm{~kg} / \mathrm{m}^{3}$ based on the homogeneous mixture as shown in Attachment. Typical natural convection conditions available in the literature and the previous analysis [4,5] were used at the boundary of the modeling domain. For the modeling analysis, effective composite thermal and material properties of the cement waste form are obtained by the literature $[6,7]$. All material and thermal properties used for the analysis are shown in Table 3. For the baseline modeling conditions of the drum, transient temperature distributions were determined by taking a sequence of time steps from time-dependent governing equations in an effort to understand how effectively the drum heat is dissipated throughout the cylindrical enclosure. Specifically, this investigation includes how long it takes to reach maximum temperature for each case. This information is important for operational performance assessments and for equipment design within the WSB facility. 
Table 2. All the cases for the thermal analysis of the 55-gallon WSB drum package

\begin{tabular}{|c|c|c|c|}
\hline Cases & $\begin{array}{c}\text { Primary } \\
\text { purpose }\end{array}$ & $\begin{array}{c}\text { Cement volume } \\
\text { percentage of drum } \\
(\%)\end{array}$ & $\begin{array}{c}\text { Height* of the enclosed air region } \\
\text { above the cement region } \\
\text { (in) }\end{array}$ \\
\hline Case 1 & Baseline & 65 & 11.55 \\
\hline Case 2 & Sensitivity & 75 & 8.25 \\
\hline Case 3 & Sensitivity & 50 & 16.5 \\
\hline
\end{tabular}

Note: *Total drum height is 33 in.

Table 3. Material and thermal properties for the analysis

\begin{tabular}{|c|c|c|c|c|}
\hline Region & $\begin{array}{c}\text { Density } \\
\left(\mathrm{kg} / \mathrm{m}^{3}\right)\end{array}$ & $\begin{array}{c}\text { Specific heat } \\
(\mathrm{J} / \mathrm{kg}-\mathrm{K})\end{array}$ & $\begin{array}{c}\text { Thermal } \\
\text { conductivity } \\
(\mathrm{W} / \mathrm{m}-\mathrm{K})\end{array}$ & $\begin{array}{c}\text { Thermal } \\
\text { diffusivity } \\
\left(\mathrm{m}^{2} / \mathrm{sec}\right)\end{array}$ \\
\hline Air & Ideal gas & 1006.4 & 0.0242 & $2.4 \times 10^{-5}$ \\
\hline Stainless steel & 8030 & 502.5 & 16.27 & $4.0 \times 10^{-6}$ \\
\hline Cement mixture & 2200 & 736 & 0.53 & $3.3 \times 10^{-7}$ \\
\hline
\end{tabular}

Note: *Air density was evaluated by ideal gas law.

\subsection{General Governing Equations}

The WSB drum forms a thin layer of stainless steel wall material surrounding the cement waste form filled inside the 55-gallon cylindrical container with the 1.52-in stainless steel center pipe filled with air. Potential cooling mechanisms of the drum system are conduction and natural convection driven by temperature gradient. The drum design considered for the present work is shown in Fig. 1. Thermal and material properties for the modeling calculations were obtained from the literature [6,7] and the information provided by the Process Science \& Engineering customer [See attachment].

The heat generated by the cement hydration will be transferred by conduction through a cementation medium and eventually will be transported to the ambient room through the physical processes of conduction and convection heat transport. The heat transfer rate at the solid-fluid interface boundary is computed using the fluid temperature gradient and heat transfer coefficient at the solid wall boundary with given ambient temperature. For the present work, the heat transfer coefficient will be estimated by the literature correlation $[5,7]$.

When cooled by natural convection, the fluid temperature gradient in the drum depends on the external gas flow field that is driven by the density gradient at the wall boundary layer and is dependent on the rate at which the gas fluid convects the heat away. 
Page: $\quad 8$ of 38

Typical air flow and temperature profiles are formed along the solid-fluid interface under actual energy transport processes such as buoyancy-driven natural convection due to the fluid temperature gradient. Temperature decreases rapidly due to the convective cooling effect within a boundary layer region. The boundary layer flow is a buoyancyinduced motion, resulting from body forces acting on masses, which arise from temperature gradients in the fluid. It is virtually impossible to observe pure heat conduction in a gas medium because as soon as a temperature difference is imposed on a fluid, natural convection currents will occur as a result of force imbalances caused by density differences. Thus energy transport is coupled to the momentum transport through the wall interface of the solid and fluid regions, but in this case, the ambient temperature and the heat transfer coefficient at the solid wall are assumed to be constant. This will lead to the reduction of computational time. However, the enclosed gas region above the cement waste region is considered a coupled momentum-energy cooling mechanism.

The two-dimensional governing equations on a control segment of the drum system in the Cartesian coordinate system are shown below.

For the mass continuity,

$$
\frac{\partial \rho}{\partial t}+\sum_{i=1}^{2}\left\{\frac{\partial\left(\rho u_{i}\right)}{\partial x_{i}}\right\}=0
$$

For the momentum equation in tensor notation,

$$
\rho\left(\frac{\partial u_{i}}{\partial t}+u_{j} \frac{\partial u_{i}}{\partial x_{j}}\right)=\frac{\partial \sigma_{i j}}{\partial x_{j}}+X_{i}
$$

where

$$
\begin{aligned}
\sigma_{i j} & =\mu\left(\frac{\partial u_{i}}{\partial x_{j}}+\frac{\partial u_{j}}{\partial x_{i}}\right) \\
\delta_{i j} & =\left(\begin{array}{l}
1 \text { for } i=j \\
0 \text { for } i \neq j
\end{array}\right) \\
X_{2} & =0 \text { for the present model. }
\end{aligned}
$$

For the energy equation,

$$
\rho C_{p} \frac{\partial T}{\partial t}+\rho C_{p} \sum_{j=1}^{2}\left\{u_{j} \frac{\partial T}{\partial x_{j}}\right\}-\sum_{i=1}^{2}\left\{\frac{\partial}{\partial x_{i}}\left(k \frac{\partial T}{\partial x_{i}}\right)\right\}-q^{\prime \prime \prime}=0
$$

Index $i$ in the equations represents the coordination direction along the $x(i=1)$ or $y(j=1)$ coordinate as shown in Fig. 1. For the present analysis, the gravitational term $X$ was used in the momentum equation to include the buoyancy-induced natural convection. The heat source term $q^{\prime \prime \prime}$ is included since a significant amount of hydration heat is transiently generated from the drum filled with the cement waste form through the cementation process. 
In eq. (4), energy terms within a control volume of a solid medium in the drum include conduction $(k \nabla T)$ and energy storage due to transients $\left(\rho C_{p} \partial T / \alpha\right)$. In this situation, the radiation term in the energy balance equation was neglected. $k$ in eq. (4) is thermal conductivity of the medium in the computational domain. This property value will be provided by input as provided in Table 3. The drum containing the cement waste with transient volumetric heat source q"' will be cooled down by a natural convection process through its wall surface as shown in Fig. 1. In this case, when wall boundary and initial conditions are provided, the governing equations are complete. They are

$-(k \nabla T)_{\text {wall }}=h_{w}\left(T-T_{\infty}\right)_{\text {wall }}$

and

$T(t=0)=T_{i}$

In eq. (2), $h_{w}$ and $T_{\infty}$ are wall heat transfer coefficient and ambient temperature, respectively. $T_{i}$ in eq. (6) is initial temperature of the computational domain.

The heat transfer coefficient at the outside wall of the column $\left(h_{w}\right)$ is obtained by using the empirical correlation available in the literature [5]. In this situation, the natural convection flow regime for the air-cooled design should be estimated based on the nondimensional Grashof number $\left(\mathrm{Gr}_{\mathrm{L}}\right)$, which is the parameter describing the ratio of buoyancy to viscous forces for a vertically-oriented cylinder with height $L$. The Grashof number performs much the same function for natural convection flow as the Reynolds (Re) number does for forced convection. Under normal conditions one may expect that the laminar-to-turbulent transition will take place at about $G r_{L} \approx 10^{9}$.

For a typical air-cooled system without forced air circulation,

$G r_{L}=\frac{g \beta L^{3}\left(T_{w}-T_{\infty}\right)}{v_{f}^{2}}$

where $L=$ characteristic length parameter $(\sim 0.85 \mathrm{~m})$,

$$
\begin{aligned}
& \beta=\text { thermal expansion coefficient }\left(=3.34 \times 10^{-3} \mathrm{~K}^{-1}\right) \\
& v_{f}=\left(\mu_{f} / \rho_{f}\right)=\text { kinematic fluid viscosity }\left(=1.60 \times 10^{-5} \mathrm{~m}^{2} / \mathrm{sec}\right) .
\end{aligned}
$$

In eq. (7), the Grashof number was estimated less than $10^{9}$ for the present conditions in order to examine the boundary layer flow regime of natural convection. This corresponds to the laminar flow according to the literature [9].

For the analysis, the natural convection regime around the WSB drum package is assumed to be laminar. As shown in Fig. 1, geometrical configurations for the present analysis involving a vertically-oriented cylindrical column. However, literature results [7] show that when the geometrical ratio of the diameter $(D)$ to the height $(L)$ is greater than or equal to $35\left(G r_{L}\right)^{-0.25}$, the natural convection correlation for vertical flat-plates can be applied to the vertical cylinder equally. For the present configurations of the 22.5-in drum,

$$
\left(\frac{D}{L}\right)_{\min .}=0.68>\left(35 G r_{L}^{-0.25}\right) \approx 0.36
$$


Page: $\quad 10$ of 38

Warner and Arpaci [5] performed an experimental investigation of natural convection in air from a vertical heated plate. The results of this study showed good agreement with the following correlation for Grashof number up to $10^{12}$ :

$N u_{L}=\left(\frac{h_{w} L}{k_{f}}\right)=0.10\left(P r_{f} G r_{L}\right)^{1 / 3}$

In Eq. (9), $P r_{f}$ is Prandtl number, and it is defined by

$\operatorname{Pr}_{f}=\frac{\mu_{f} C p_{f}}{k_{f}}$

In eq. (9) $h_{w}$ is natural convection heat transfer coefficient at the heated solid wall. $k_{f}$ is thermal conductivity of fluid at the fluid temperature $T_{f}$. Potential range of heat transfer coefficients at the wall surface of the 55-gallon drum was estimated as shown in Fig. 4. Averaged heat transfer coefficient of $2.5 \mathrm{~W} / \mathrm{m}^{2}-\mathrm{K}$ was used for the present calculations.

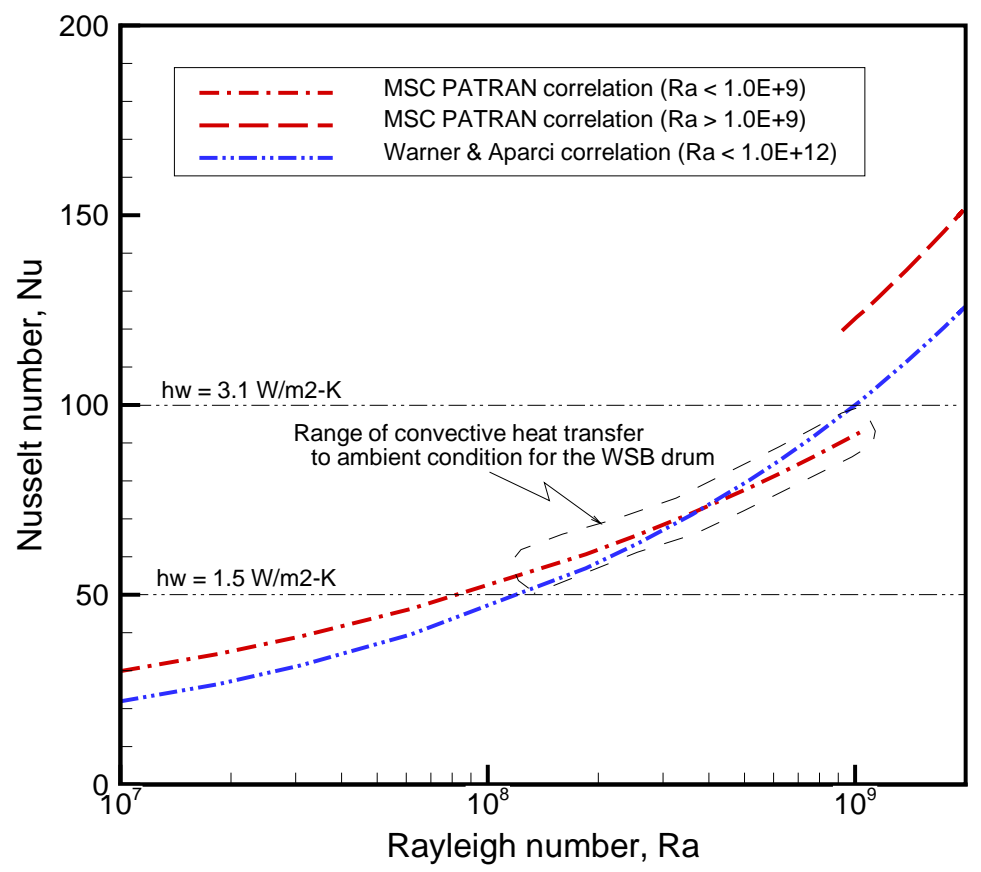

Figure 4. Heat transfer coefficients at the wall surface of the 55-gallon drum for the present modeling calculations 
These governing equations are applied to the two-dimensional computation domain depending on the physical model for the heat transfer analysis of the WSB drum assuming that the radiative heat transfer of the drum is negligible. Equation (1) provides heat source term (q"' in eq. (4)) as function of transient time in hours for the cement region. Average heat loading over the 70 -hour transient period is about 0.37 watts per unit kilogram of waste form from the measurements of the simulated HAW sample. For the analysis of all three cases as shown in Table 2, transient calculations were performed for thermal performance of the WSB package. The steady-state calculations were also performed to examine how efficiently the averaged hydration heat loading is dissipated through the enclosed drum package. In this case, averaged heat loading of about $821 \mathrm{~W} / \mathrm{m}^{3}$, corresponding to $0.373 \mathrm{~W} / \mathrm{kg}$ as shown in Table 1 , was used as volumetric heat source q"' in the energy equation.

The material and thermal properties for the components of the 55-gallon drum package in a WSB facility are provided in Table 3. Using these thermal properties, a twodimensional transient heat transfer model was performed to predict transient thermal responses of the WSB drum partially filled with the cement waste form. For computational efficiency, effective thermal conductivity for the composite cement region was used. Thus, computational time can be reduced by modeling a single-material region with the effective thermal conductivity instead of modeling a multi-material region composed of several different materials. This leads to a reduction in the computational time and effort with about 95\% accuracy in the temperature predictions.

The two-dimensional geometry file was created using the multi-block preprocessor of the Fluent ${ }^{\mathrm{TM}}$ code [3] under the body-fitted coordinate system, which allows the treatment of non-orthogonal geometries. The present model consists of 4 element blocks and 3 different material zones on the $x$-y computational plane. Non-uniform two-dimensional structured meshes of the computational domain were used to capture the smooth temperature gradient across the boundary zone of the two different material regions. Typical modeling boundaries for the cases considered here are shown in Table 3. Implicit and iterative solution techniques were used to solve the transient governing equations [3,4].

The overall energy balance should be checked to demonstrate the adequacy of the grid fineness used. This was done by using eq. (11).

$R=-\int_{A_{W}} q_{W}^{\prime \prime} d A+q " V_{F}$

The volumetric heat source term, q"', in eq. (11) is given by the code input. $A_{w}$ in the equation is the entire wall surface area for the heat transfer of the drum package cooled by the ambient conditions. For all the cases considered here, energy residual $(R)$ is less than about 0.1 watt. For the present analysis, an optimum grid of about 12,000 cells has been established from the grid sensitivity analysis under the Linux HP DL585 platform. Non-uniform two-dimensional meshes used for the computational analysis of the $65 \%$ filled drum package are shown in Fig. 5. 


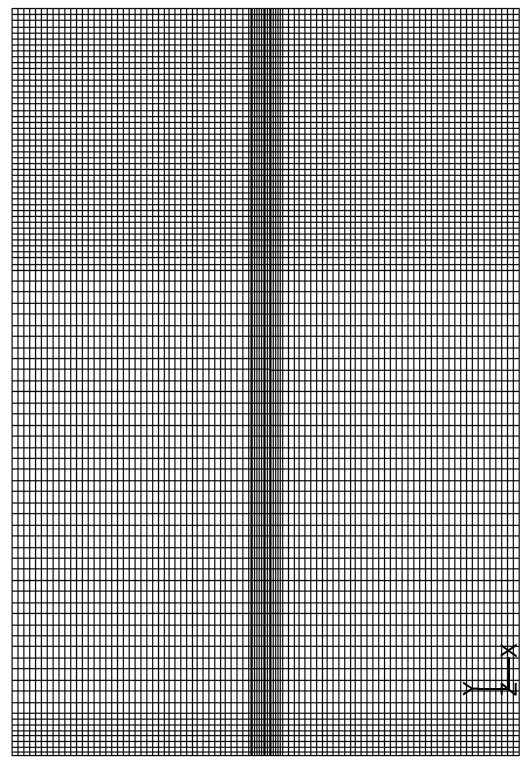

Figure 5. Two-dimensional meshes for the computational domain used for the present analysis

\subsection{Modeling Assumptions and Design Parameters}

In order to achieve the modeling objectives, a CFD approach is taken by applying the previous solution method [4]. This work will start with the baseline model, assuming that the cement waste form fills the WSB drum by $65 \%$ in volume for the treatment and solidification of the radioactive liquid waste streams generated by the PDCF and MFFF.

Transient heat transfer calculations for the 55-gallon WSB drum will be performed for the evaluation of the thermal performance for the drum package containing hydration heat source associated with the current baseline cement waste form.

Transient calculations will use the following main assumptions:

- Pouring process of the cement waste form into the drum is assumed to be instantaneous.

- For the evaluation of thermal performance for the WSB drum, there is no flow communication through the sintered metal filter located at the top center of the drum.

- Radiative heat transfer is negligible compared to the conduction and convection cooling mechanisms since maximum component temperatures are expected to be lower than $100^{\circ} \mathrm{C}$.

- For conservative estimate, there is no heat transfer through the bottom surface of the drum package. 
- Top surface of the waste form cementation is formed in a horizontally smooth way.

- No air pocket within the cement region is generated through the mixing and cementation process of the WSB waste form.

- For conservative heat transfer calculations, the heat source was estimated for a uniformly-distributed cement region.

- Constant thermal conductivity for each material was assumed instead of considering temperature-dependency for the energy equation.

Based on the modeling assumptions, the models will take a two-dimensional computational approach to calculate transient temperature distributions for the WSB drum package partially filled with the cement waste form containing transient heat source. A finite volume CFD code, FLUENT [3], will be used to perform the thermal analysis of the drum package. Prototypic drum geometry is meshed in a non-uniform way. The modeling domain to be used for the analysis is presented in Fig. 5. Baseline design and operating conditions of the heat transfer analysis are presented in Table 1.

As needed, based on the results of the transient evaluations, steady-state calculations will be conducted under the same conditions listed above to compare the temperature distributions and buoyancy-driven flow characteristics associated with natural convection cooling mechanism. The modeling results will provide quantitative information associated with the optimal operating configuration such as cooling time and waste form loading.

\section{Results and Discussions}

An axi-symmetric two-dimensional approach has been taken to compute temperature distributions within the modeling domain shown in Fig. 2 and to investigate transient temperature responses to hydration heat loads for the enclosed 55-gallon drum partially filled with cement waste form. For three modeling Cases 1, 2, and 3, these drums are assumed to be cooled primarily by natural convection at the external drum walls and through the enclosed gas region above the cement region. For Case 1,65\%-filled drum was considered as the baseline operating condition to evaluate maximum cement waste and drum surface temperatures under convective cooling mechanism. Modeling conditions used for the calculations are summarized in Tables 1 and 2.

\subsection{Benchmarking Results}

A theoretical approach for transient conduction heat transfer of an infinite slab layer with initially uniform temperature was taken to verify the present computational model against the theoretical results under simple geometrical conditions. Modeling predictions for buoyancy-driven flow due to temperature gradient in a thin rectangular enclosure were also compared with the theoretical results. These evaluations were conducted to benchmark and validate the important heat transfer behaviors of the present model associated with transient thermal response and buoyancy-driven natural convection. 


\subsubsection{Transient Conduction Response to Sudden Cooling}

For the benchmarking test of the model used for the present analysis, an infinite plate of thickness L shown in Fig. 6 was considered. Initially the plate is at uniform temperature $T_{i}$, and at time zero the surfaces are suddenly lowered to $T=T_{w}$. Under transient conditions, the energy equation for the slab with effective thermal conductivity $k_{b, \text { eff }}$ becomes

$$
\begin{aligned}
\frac{\partial T(x, t)}{\partial t} & =\left(\frac{k_{b, \text { eff }}}{\rho C_{p}}\right)\left(\frac{\partial^{2} T(x, t)}{\partial x^{2}}\right) \\
& =\alpha\left(\frac{\partial^{2} T(x, t)}{\partial x^{2}}\right)
\end{aligned}
$$

By using the separation of variable technique, final series solution at position $x$ and time $t$ can be obtained from the initial and boundary conditions. That is,

$$
T(x, t)=T_{w}+\left(T_{i}-T_{w}\right)\left(\frac{4}{\pi}\right)\left[\sum_{n=1}^{\infty} \frac{1}{n} \exp \left\{-\alpha\left(\frac{n \pi}{L}\right)^{2} t\right\} \sin \left(\frac{n \pi x}{L}\right)\right]_{n=1,3,5,7,----}
$$

Material and thermal properties used for the benchmarking test are provided in Table 4. When an infinite slab plate as shown Fig. 6 is $100^{\circ} \mathrm{C}$ initially, and its wall surfaces are suddenly cooled down to $20^{\circ} \mathrm{C}$, the transient temperature responses are benchmarked against the theoretical results shown in Eq. (13). The modeling results are quantitatively compared to the theoretical values in Table 5. The modeling predictions are in agreement with theory within about $0.5 \%$. Detailed spatial and transient distributions are also compared with the theoretical results as shown in Figs. 7 and 8.

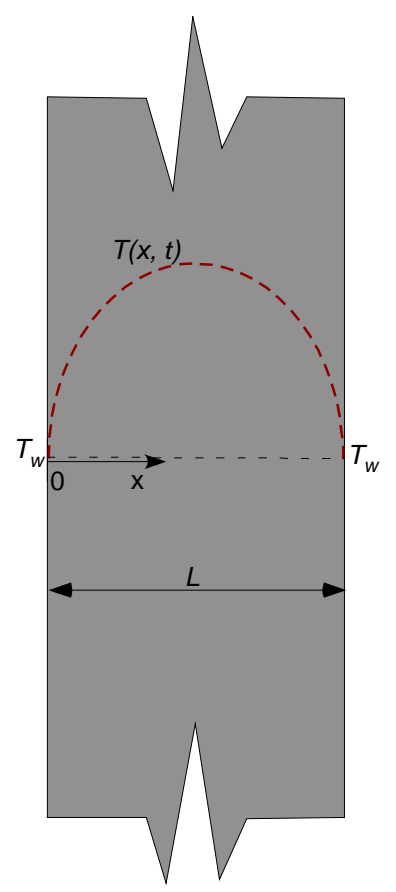

Figure 6. Infinite slab plate subjected to sudden cooling of surfaces 
Table 4. Material and thermal properties used for the benchmarking analysis

\begin{tabular}{|c|c|c|c|}
\hline \multirow{2}{*}{ Parameters } & \multicolumn{3}{|c|}{ Material and thermal properties } \\
\cline { 2 - 4 } & Density, $\rho$ & Specific heat, $C_{p}$ & $\begin{array}{c}\text { Thermal conductivity, } \\
k_{b, \text { eff }}\end{array}$ \\
\hline Values & $8000 \mathrm{~kg} / \mathrm{m}^{3}$ & $500 \mathrm{~J} / \mathrm{kg}-\mathrm{K}$ & $20.0 \mathrm{~W} / \mathrm{m}-\mathrm{K}$ \\
\hline
\end{tabular}

Table 5. Quantitative comparison of the modeling predictions with the theoretical results

\begin{tabular}{|c|c|c|c|}
\hline $\begin{array}{c}\text { Transient time } \\
(\mathrm{sec})\end{array}$ & $\begin{array}{c}\text { Modeling predictions } \\
\left({ }^{\circ} \mathrm{C}\right)\end{array}$ & $\begin{array}{c}\text { Theoretical values } \\
\left({ }^{\circ} \mathrm{C}\right)\end{array}$ & $\begin{array}{c}\text { Relative errors } \\
(\%)\end{array}$ \\
\hline 1 & 99.63 & 99.75 & 0.12 \\
\hline 5 & 74.80 & 74.84 & 0.04 \\
\hline 10 & 49.70 & 49.66 & 0.07 \\
\hline 14 & 38.16 & 38.11 & 0.13 \\
\hline 22 & 26.79 & 26.75 & 0.14 \\
\hline 30 & 22.54 & 22.52 & 0.12 \\
\hline 40 & 20.75 & 20.73 & 0.07 \\
\hline 50 & 20.23 & 20.21 & 0.06 \\
\hline 60 & 20.07 & 20.06 & 0.03 \\
\hline
\end{tabular}




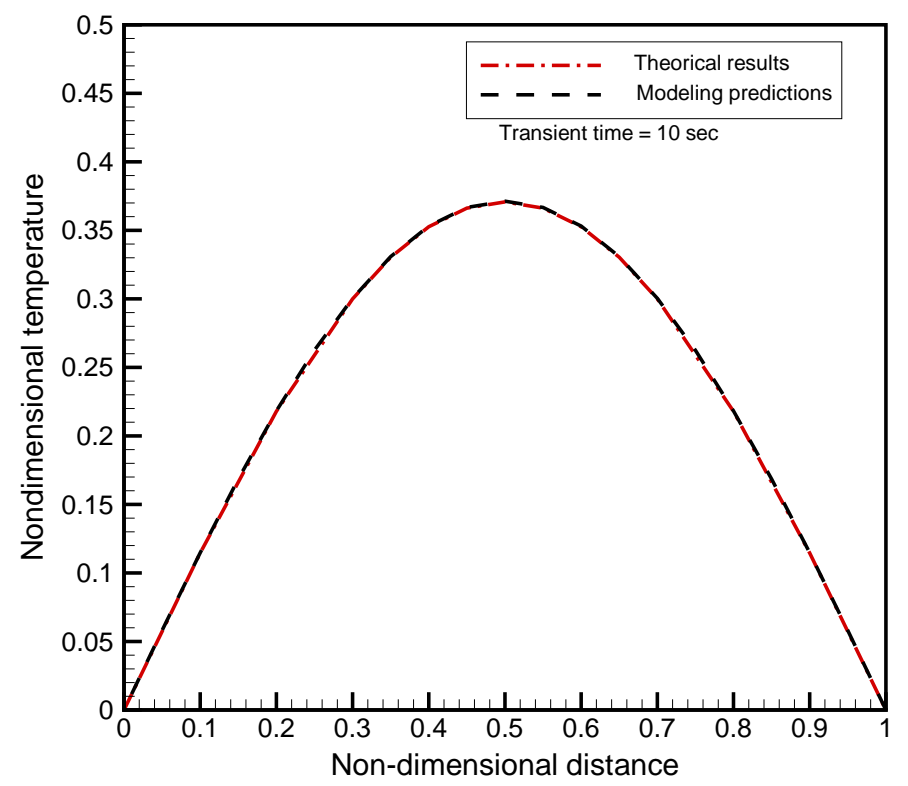

Figure 7. Benchmarking results of the present model against the theoretical calculations for the spatial temperature distributions across the slab at 10 seconds of transient time

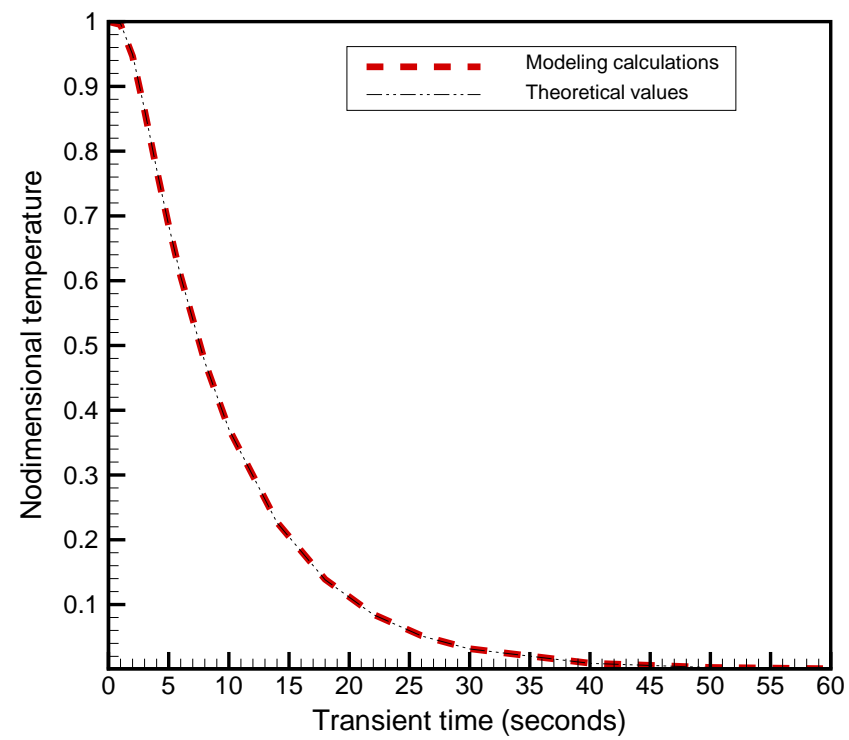

Non-dimensional temperature, $\theta=\left\{\frac{\left(T(x, t)-T_{w}\right)}{\left(T_{i}(x, t=0)-T_{w}\right)}\right\}$

Figure 8. Benchmarking results of the present model against the theoretical calculations for the transient thermal response 


\subsubsection{Natural Convection inside a Rectangular Enclosure}

The two-dimensional natural convection problem with specified boundary temperatures consists of a rectangular enclosure with adiabatic horizontal walls and isothermal vertical walls maintained at a fixed temperature difference. The temperature differences between the hot and cold walls are $10^{\circ} \mathrm{C}$ for the first case and $25^{\circ} \mathrm{C}$ for the second case. The model calculation is based on conduction and natural convection of heat through the gas medium. The height $(\mathrm{H})$ and width $(\mathrm{L})$ of the enclosure were arbitrarily chosen to be $1 \mathrm{~m}$ and $0.0254 \mathrm{~m}$ respectively, which is an aspect ratio of about 40 and generally considered a narrow slit geometry. A schematic of this problem is shown in Fig. 9.

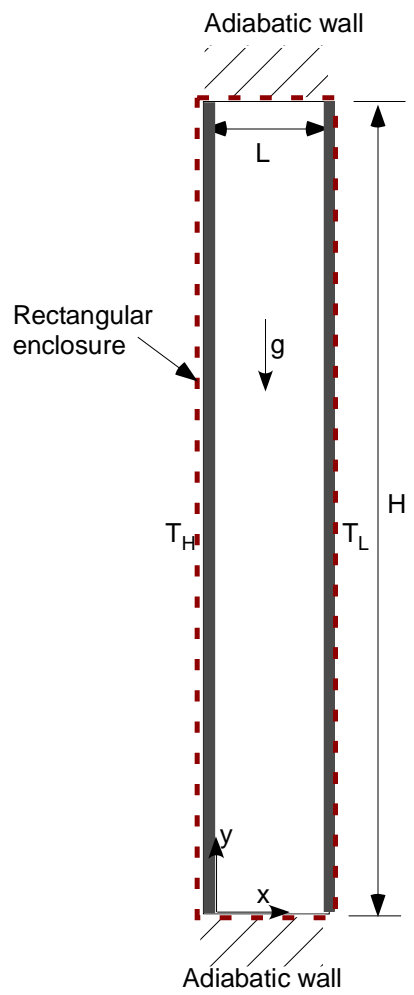

Figure 9. Natural convection driven by the temperature gradient between two different wall temperatures inside a rectangular slit enclosure.

An analytical solution for the natural convection problem can be determined for an idealized representation of the problem as fully developed flow between two infinite parallel plates as shown in Fig. 9. The momentum and energy equations for this twodimensional problem can be expressed in the following form:

$g \beta\left(T-T_{m}\right)+\left(\frac{\mu}{\rho}\right)\left(\frac{\partial^{2} u}{\partial x^{2}}\right)=0$ 
$\left(\frac{\partial^{2} T}{\partial x^{2}}\right)=0$

where $u$ is the $y$-direction component of the velocity and the Boussinesq approximation has been applied to the gravitational term of Eq. (14). The reference temperature for the problem is taken as

$T_{m}=\frac{1}{2}\left(T_{H}-T_{L}\right)$

With two boundary conditions, $T=T_{H}$ at $\mathrm{x}=0$ and $T=T_{\mathrm{L}}$ at $\mathrm{x}=\mathrm{L}$,

energy equation, Eq. (15), can be solved to give

$T(x)=T_{H}-\left(T_{H}-T_{L}\right)\left(\frac{x}{L}\right)$

Substituing eq. (16) and (17) into Eq. (14) results in

$$
\frac{d^{2} u(x)}{d x^{2}}=\left(\frac{g \beta \rho}{\mu}\right)\left(T_{H}-T_{m}\right)\left(2 \frac{x}{L}-1\right)
$$

Integrating once gives

$$
\frac{d u(x)}{d x}=\left(\frac{g \beta \rho}{\mu}\right)\left(T_{H}-T_{m}\right)\left(\frac{x^{2}}{L}-x\right)+A
$$

Integrating a second time gives

$$
u(x)=\left(\frac{g \beta \rho}{\mu}\right)\left(T_{H}-T_{m}\right)\left(\frac{x^{3}}{3 L}-\frac{x^{2}}{2}\right)+A x+B
$$

Using no-slip boundary condition $(u(x)=0)$ at $x=0$ and $x=\mathrm{L}$ allows the constants $A$ and $B$ of eqs. (19) and (20) to be determined.

$$
\begin{aligned}
& A=\frac{g \beta \rho}{6 \mu} L\left(T_{H}-T_{m}\right) \\
& B=0
\end{aligned}
$$

Substituting the constants of Eq. (21) into Eq. (20) results in the following expression for $u(x)$ :

$$
u(x)=\left(\frac{g \beta \rho}{12 \mu}\right) L^{2}\left(T_{H}-T_{L}\right)\left\{2\left(\frac{x}{L}\right)^{3}-3\left(\frac{x}{L}\right)^{2}+\left(\frac{x}{L}\right)\right\}
$$

This expression shows extrema at $x / L=0.211$ and 0.789 . The magnitude of the term in brackets at the extrema is \pm 0.0962 . This value can be multiplied by the physical constants in Eq. (22) and compared to the numerical results. The physical constants used for the benchmarking test are 
$\rho=0.1626 \mathrm{~kg} / \mathrm{m}^{3}$

$\beta=2.85 \times 10^{-3} K^{-1}$

$g=9.81 \mathrm{~m} / \mathrm{sec}^{2}$

$\mu=2.0 \times 10^{-5} \mathrm{~N}-\mathrm{sec} / \mathrm{m}^{2}$

$L=0.0254 \mathrm{~m}$

With these values, the maximum velocity at the mid-plane of the rectangular enclosure is theoretically

Case A: $u= \pm 0.01176 \mathrm{~m} / \mathrm{sec}$ for $\Delta T=\left(T_{H}-T_{L}\right)=10 \mathrm{~K}$

Case B: $u= \pm 0.02939 \mathrm{~m} / \mathrm{sec}$ for $\Delta T=\left(T_{H}-T_{L}\right)=25 \mathrm{~K}$

The profile of velocity across the width of the gap is as important as the maximum value within the gap of the slit geometry. The theoretical velocity distributions for a rectangular enclosure were compared with the modeling results for the two temperature differences, $10 \mathrm{~K}$ and $25 \mathrm{~K}$, under buoyancy-driven natural convection conditions. The validated results are shown in Fig. 10, where the model predictions and theoretical results show excellent agreement. Table 6 also shows comparison of the peak values predicted by the computational model with the theoretical ones. Based on these evaluations, the benchmarking was considered complete and the model was considered validated. 


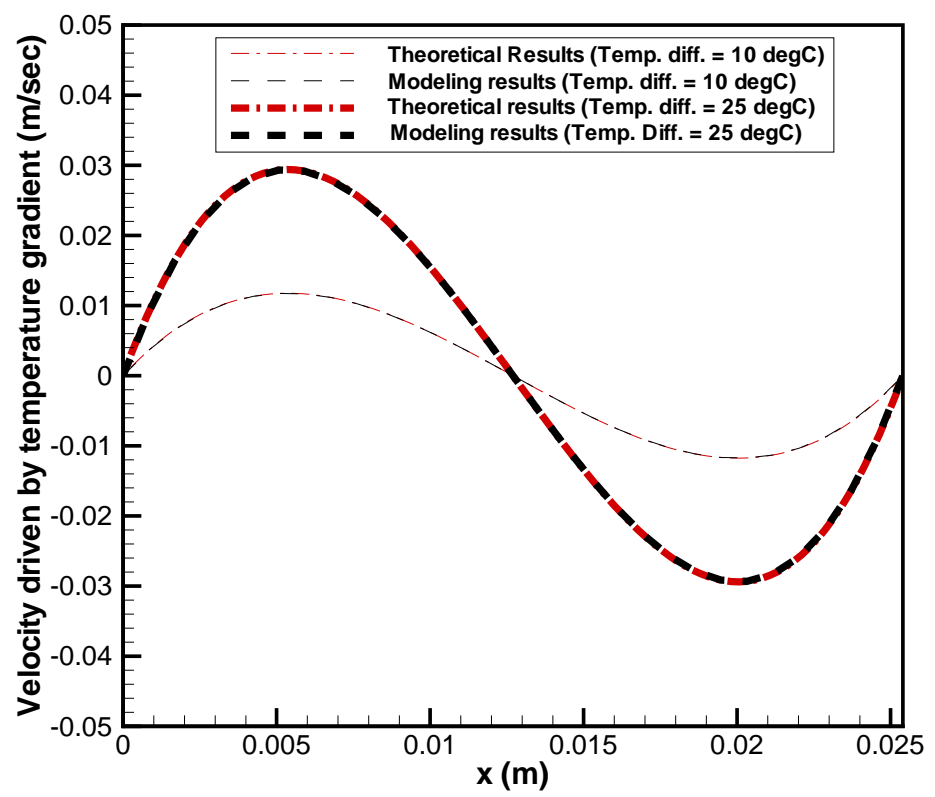

Figure 10. Comparison of the modeling predictions with theoretical results for the two different temperature differences between the two plates as shown in Fig. 8.

Table 6. Comparison of maximum natural convective velocities driven by temperature gradients between theoretical results and modeling predictions.

\begin{tabular}{|c|c|c|c|c|}
\hline \multirow{2}{*}{$\begin{array}{c}\text { Two } \\
\text { cases }\end{array}$} & \multirow{2}{*}{$\begin{array}{c}\text { Temperature difference } \\
\text { between two walls } \\
\left({ }^{\circ} \mathrm{C}\right)\end{array}$} & \multicolumn{2}{|c|}{$\begin{array}{c}\text { Max. convective velocity } \\
(\mathrm{m} / \mathrm{sec})\end{array}$} & \multirow{2}{*}{$\begin{array}{c}\text { Relative error } \\
(\%)\end{array}$} \\
\cline { 3 - 4 } & 10 & Theory & Model & \\
\hline Case A & 25 & 0.01176 & 0.01171 & 0.43 \\
\hline Case B & & 0.02939 & 0.02927 & 0.44 \\
\hline
\end{tabular}




\subsection{Modeling Results}

The validated model was subsequently used for thermal performance analysis of the WSB drum geometry partially filled with the cement waste form containing transient hydration heat source. Table 7 shows transient maximum drum content and surface temperatures for the three different volumes of the cement waste form in a WSB drum. The results reveal that the maximum temperature of the WSB drum loaded to $75 \%$ cement waste form does not exceed the liquid phase boiling point of $\sim 100^{\circ} \mathrm{C}$ under natural convective cooling conditions (maximum temperature: $96^{\circ} \mathrm{C}$ ). Figure 11 shows transient maximum drum surface temperature and maximum waste content temperature for the 65\%-filled drum package containing transient hydration heat source as provided in Fig. 2 when initial waste and ambient temperatures are $43^{\circ} \mathrm{C}$ and $27^{\circ} \mathrm{C}$, respectively. In the figure, steady state temperatures based on the heat source averaged over the 70 hour period are compared with the transient temperatures under the same boundary conditions. It is noted that transient maximum temperatures reach steady-state maximum temperatures in about 20 hours when initial temperature of the cement waste form is $43^{\circ} \mathrm{C}$.

When the baseline drum package is filled with the cement waste form by $65 \%$ and initial temperature is $43^{\circ} \mathrm{C}$, transient drum surface temperature distributions along the elevation height from the bottom to top of the external drum surface are shown in Fig. 12. Steady state temperature distributions for the heat loading averaged over the 70hour period are compared in the figure. It is noted that there is a large temperature drop across the solid-fluid interface due to the additional cooling mechanism driven by internal natural circulation inside the enclosed void space above the cement region.

Figure 13 shows temperature contour plot for the central plane at 32-hour transient time with initial conditions of $43^{\circ} \mathrm{C}$ waste temperature when the baseline loading of $65 \%$-filled drum is cooled by $26.85^{\circ} \mathrm{C}$ ambient temperature under natural convective cooling mechanism. Density distributions for the enclosed air region inside the WSB drum at 32 hours under the baseline loading conditions with the same initial and boundary conditions are shown in Fig. 14. The results show that a large gas plume is generated by a steep temperature gradient along the center tube of the enclosure above the cement waste region. The corresponding air flow patterns driven by density gradient inside the air space above the cement are presented in Fig. 15. It is noted that natural buoyancy drives air circulation velocity of about $1 \mathrm{ft} / \mathrm{sec}$ in 12-in tall enclosure when peak transient temperature is reached under the baseline drum loaded with $65 \%$ volume of the cement waste form.

Figure 16 shows transient snapshots of temperature distributions across the central plane of the 55-gallon drum filled with the cement waste by $65 \%$ when initial waste and ambient temperatures are $43^{\circ} \mathrm{C}$ and $26.85^{\circ} \mathrm{C}$, respectively. In the figure, red color is indicated as $95.46^{\circ} \mathrm{C}$, and blue one is $26.85^{\circ} \mathrm{C}$. The corresponding air flow patterns generated by temperature gradient are shown in Fig. 17 . It is clearly shown that when temperature gradient across the thermal boundary layer becomes larger, buoyancydriven velocity becomes larger, leading to the higher ratio of convection to conduction cooling mechanism. In this case, the convection-to-conduction ratio, referred to as Nusselt number, is about 80 when the waste form temperature reaches peak value at transient time of 32 hours under the baseline drum loading (Case 1). This is consistent with the literature information [9]. 
Two different initial waste temperatures of $43^{\circ} \mathrm{C}$ and $26.85^{\circ} \mathrm{C}$ were considered to quantify the sensitivity of transient thermal responses to the same heat loading. Figure 18 compares transient maximum drum surface and waste temperatures between the two different initial waste temperatures under the transient heat source as provided by Fig. 2 . The results show that when initial temperature of the cement waste form changes from $43^{\circ} \mathrm{C}$ to about $27^{\circ} \mathrm{C}$, maximum temperature of the WSB drum is reduced by about $6^{\circ} \mathrm{C}$ at 32 hours of transient time.

When the WSB drum is partially filled with different volumes of the cement waste form, thermal responses to the transient hydration heat loading were evaluated to quantify how quickly the heat loading is dissipated into the ambient environment through the drum package. As shown in Fig. 19, the modeling results of the transient maximum drum surface and cement waste temperatures are compared for different loadings of cement waste in a drum container when initial waste and ambient temperatures are $43^{\circ} \mathrm{C}$ and $26.85^{\circ} \mathrm{C}$, respectively. Table 7 also shows quantitative comparison of transient maximum cement and drum surface temperatures for three different volumes of the cement waste form.

Figure 20 compares the temperature distributions cooled by natural convection at 32hour transient time for different sizes of gas enclosures above the top surface of the waste form cement region due to the different loading volumes of the cement waste form under the same color scale. As color scale in the figue, red region represents temperature higher than $96.0^{\circ} \mathrm{C}$, and blue one has $26.85^{\circ} \mathrm{C}$. Figure 21 shows qualitative comparison of natural circulation patterns driven by the temperature gradients shown in Fig. 20 for different heights of gas enclosures above the top surface of the cement waste form region due to the different loading volume of the cement waste form at the peak temperature time of 32 hours when red region has velocity higher than $0.39 \mathrm{~m} / \mathrm{sec}$, and blue one has zero velocity. Table 8 compares quantitative ratios of convection to conduction cooling mechanisms for different heights $(\mathrm{H})$ of the air enclosure above the cement waste form with the same heat loading at 32 hours of transient time during WSB drum storage. These values are referred to as Nusselt number in the literature, and they are representative of the coolability increase of the enclosed waste package due to the buoyancy-driven cooling mechanism such as natural convection during the interim WSB drum storage. It is clearly shown that increasing vertical height of the gas enclosure results in higher coolability due to the increased gas motion.

The results indicate that when the loading volume increases from 50 vol\% to 75 vol\% for the enclosed drum with initial cement temperature $43^{\circ} \mathrm{C}$ and ambient temperature $26.85^{\circ} \mathrm{C}$, peak temperature increase over the entire drum will be about $2^{\circ} \mathrm{C}$ for the cement region containing the hydration heat source as defined in Eq. (1) and about $0.5^{\circ} \mathrm{C}$ for the external surface of the drum package. This means that smaller height of the gas enclosure drives slower gas movement due to the smaller gravity difference between the heated surface and the cooled one under the same heat loading and ambient conditions.

The results demonstrate that the buoyancy-driven gas circulation in the enclosed region above the cement region provides the primary cooling mechanism in reducing the peak drum temperature. Table 9 shows a quantitative comparison of maximum waste and drum surface temperatures under the various loading conditions of the WSB drum.

The transient thermal response of a conduction medium containing a heat source to the cooling environment at a lower temperature is closely related to its thermal diffusivity. 
The thermal diffusivity, $\alpha$, is defined as the ratio of thermal conductivity to the product of density and specific heat. As shown in Table 3, the drum media during hydration process have small $\alpha$ values of $3.3 \times 10^{-3} \mathrm{~cm}^{2} / \mathrm{sec}$ for cement waste form. This parameter is a measure of temperature-wave penetration depth for a given time. The results showed that peak temperature of the WSB drum containing heat source was reached at about 32 hours although hydration heat was peak at about 17.5 hours since the initiation of the cementation process. The relatively slow transient thermal response of the drum to the heat load is mainly due to the low thermal diffusivity of the cement waste form material as indicated in the table. The results demonstrate that a naturallycooled (ambient drum temperature of $27^{\circ} \mathrm{C}$ with no forced ventilation), 22.5-in drum package under all loading conditions of the cement waste form considered here can stay lower than $100^{\circ} \mathrm{C}$ in WSB facility.

The results show that increasing the cement volume from $50 \%$ to $75 \%$ does not greatly impact the maximum temperature or the heat rate. As shown in Fig. 20, it is noted that the 1.52-in central stainless steel pipe clearly provides an effective conduction path in dissipating the hydration heat from the cement region containing heat source to the cooler ambient. 
Page: $\quad 24$ of 38

Table 7. Transient maximum cement and drum surface temperatures for three different volumes of the cement waste form

\begin{tabular}{|c|c|c|c|c|}
\hline \multirow{2}{*}{ Cases } & \multicolumn{3}{|c|}{ Max. cement temp. (Max. surface temp.), ${ }^{\circ} \mathbf{C}$} \\
\cline { 2 - 5 } & Case 1 (Baseline) & Case 2 & Case 3 \\
\hline \multirow{2}{*}{ Cement volume \% of the drum } & $65 \%$ & $75 \%$ & $50 \%$ \\
\hline \multirow{4}{*}{$\begin{array}{c}\text { Transient time } \\
\text { (hours) }\end{array}$} & 0 (initial) & $43(43)$ & $43(43)$ & $43(43)$ \\
\cline { 2 - 5 } & 12 & $56.3(42.8)$ & $56.4(42.8)$ & $56.3(42.8)$ \\
\cline { 2 - 5 } & 24 & $87.5(57.6)$ & $87.7(57.6)$ & $86.7(57.4)$ \\
\cline { 2 - 5 } & 32 & $95.5(59.0)$ & $95.9(59.1)$ & $93.9(58.6)$ \\
\cline { 2 - 5 } & 48 & $85.1(52.8)$ & $86.0(53.0)$ & $82.2(51.8)$ \\
\cline { 2 - 5 } & 70 & $64.0(43.3)$ & $65.1(43.7)$ & $61.0(42.3)$ \\
\hline
\end{tabular}

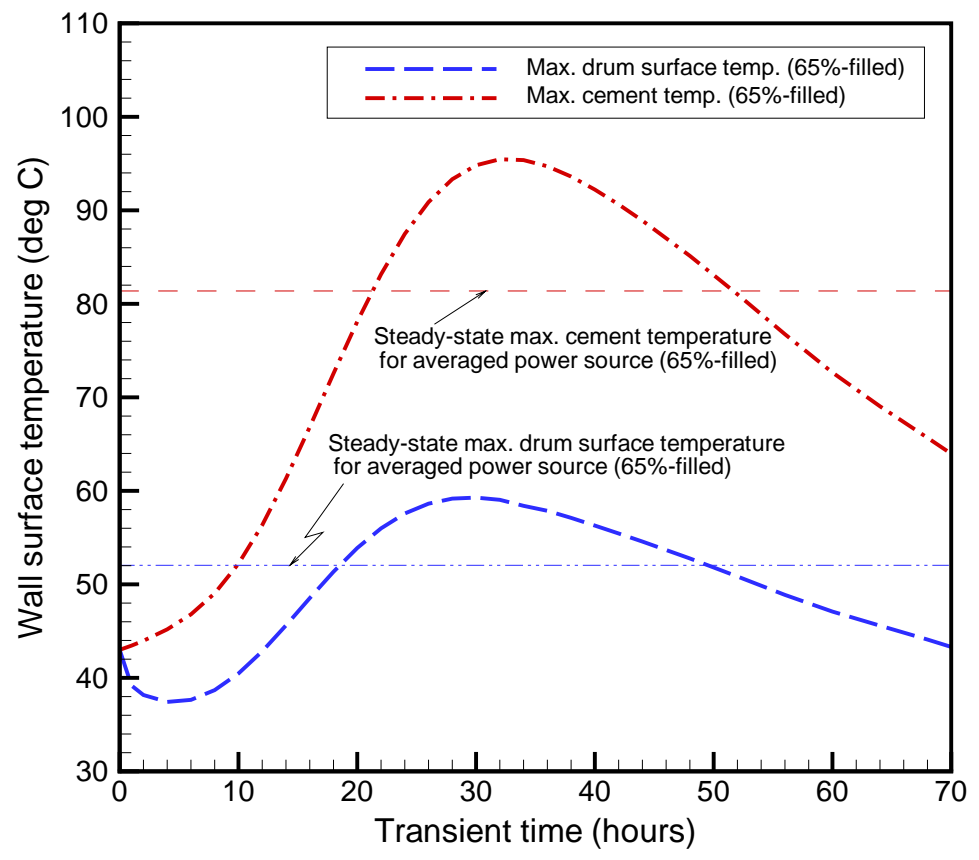

Figure 11. Transient maximum drum surface temperature and maximum waste temperature for $65 \%$-filled heat source provided by Fig. 2 (Initial waste temperature $=43^{\circ} \mathrm{C}$ and ambient temperature $=27^{\circ} \mathrm{C}$, and steady state temperatures based on the heat source averaged over the 70 -hour period). 


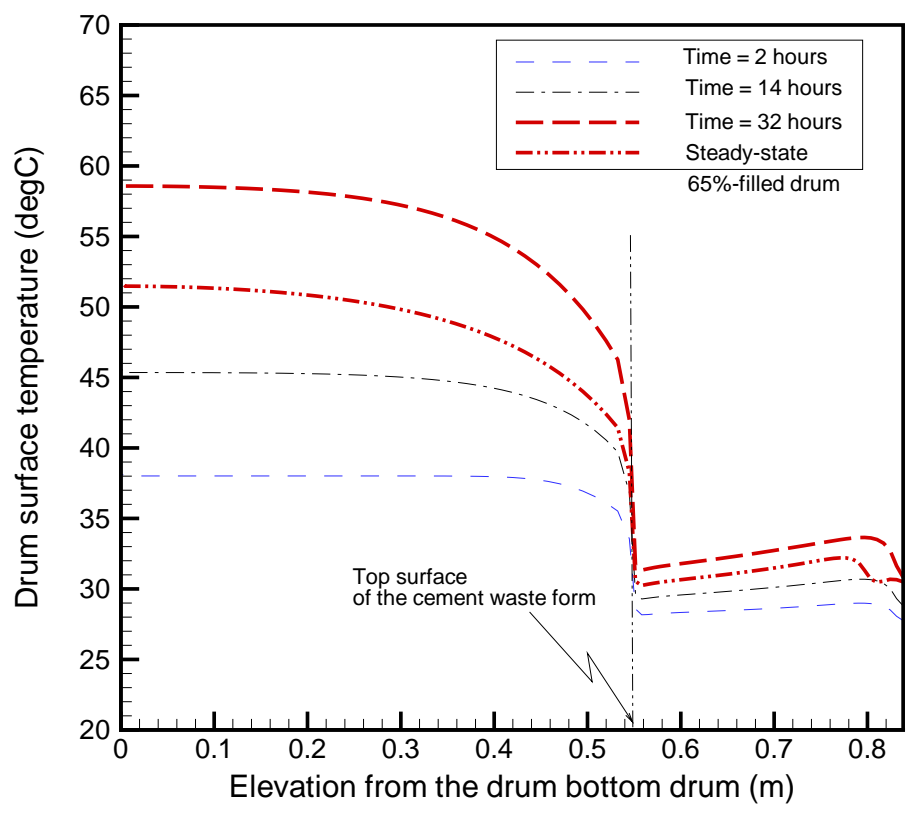

Figure 12. Transient drum surface temperature distributions for $65 \%$-filled heat source provided by Fig. 2 (Initial waste temperature $=43^{\circ} \mathrm{C}$ and ambient temperature $=27^{\circ} \mathrm{C}$, and steady state temperatures based on the heat source averaged over the 70-hour period). 


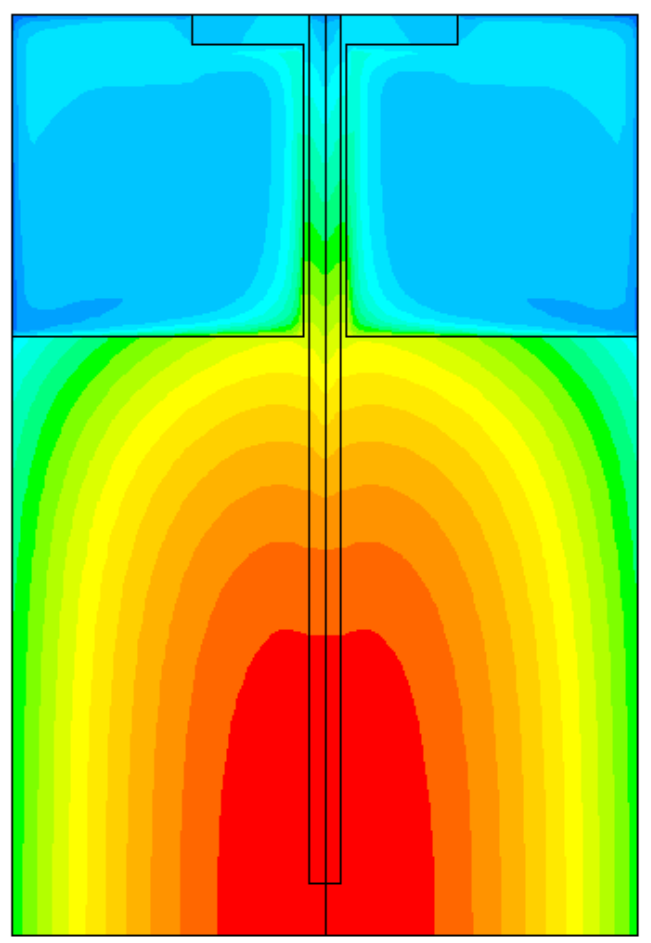

$\infty$
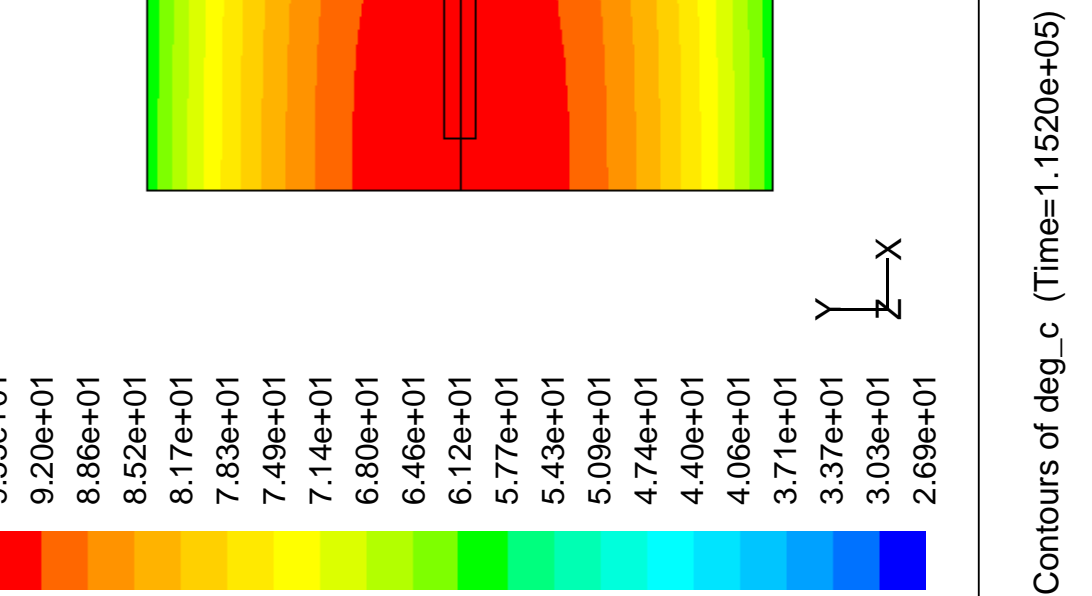

Figure 13. Temperature contour plot at 32 hours after initial conditions with initial waste temperature $=43^{\circ} \mathrm{C}$ and ambient temperature $=27^{\circ} \mathrm{C}(65 \%$-filled drum) . 


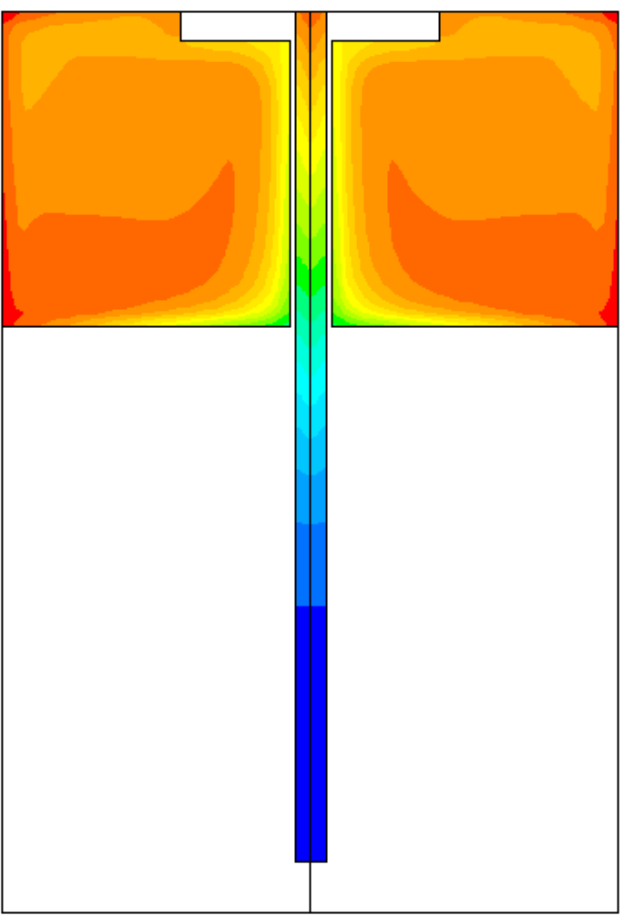

$\infty$

귱

ตำ

更

음

ఫ్ర

్ㅣㅁ

용

离

ஸै

与

岂

กำ

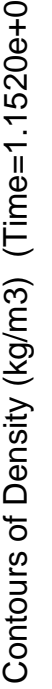
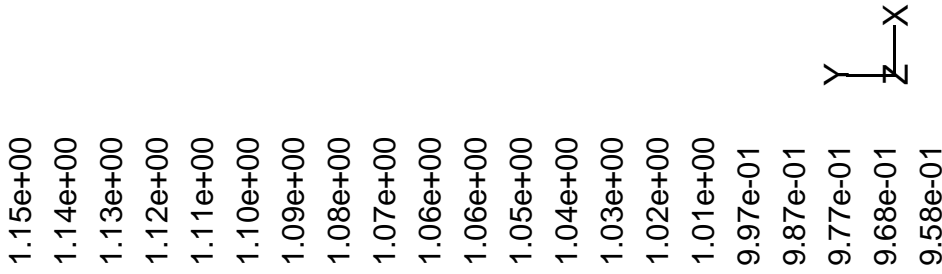

Figure 14. Density distributions for the enclosed gas regions inside the drum at 32 hours for initial waste temperature $=43^{\circ} \mathrm{C}$ and ambient temperature $=27^{\circ} \mathrm{C}$ under the baseline drum (65\%-filled drum). 

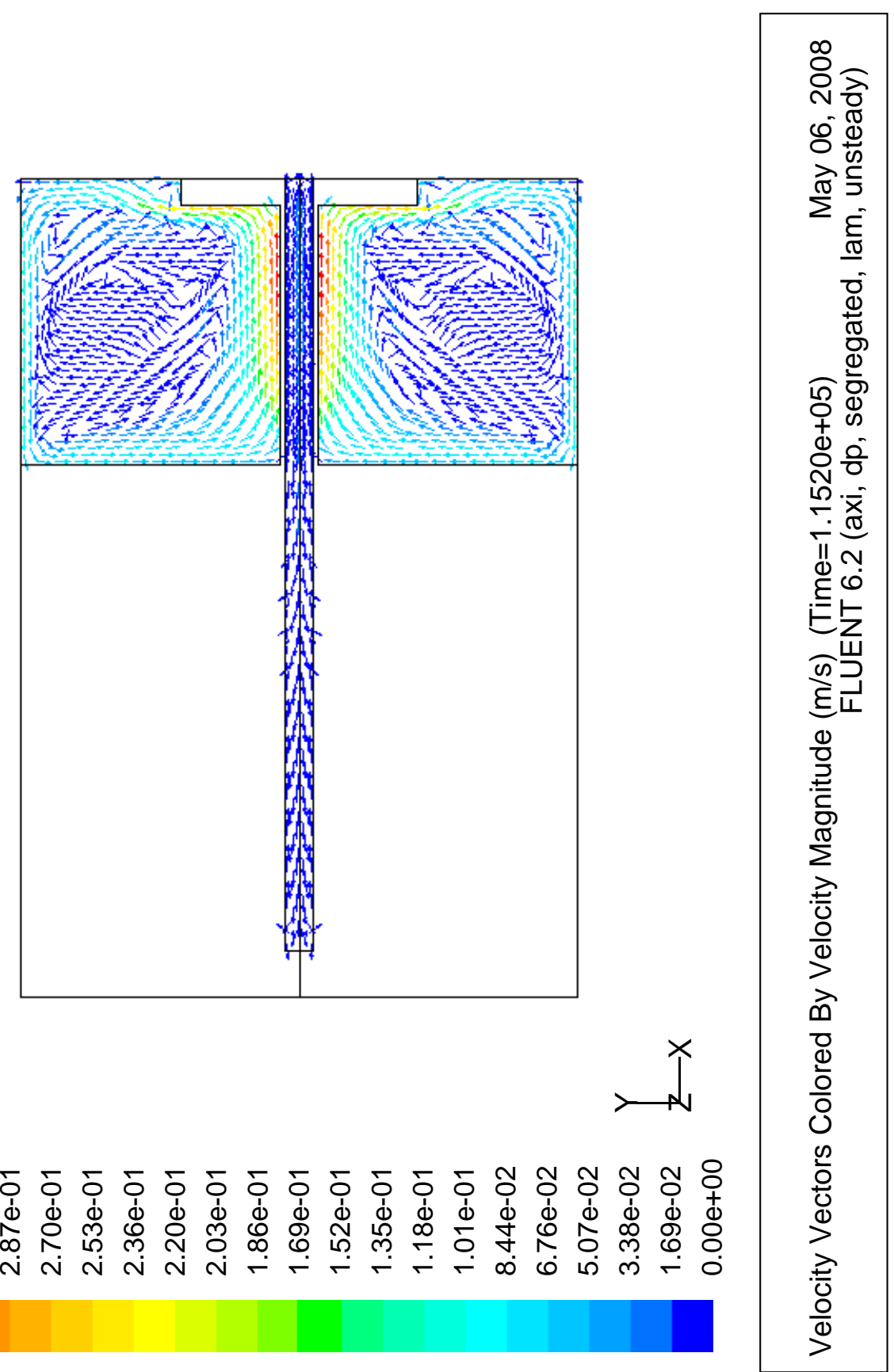

Figure 15. Air flow patterns driven by temperature gradient inside the vapor space above the cement at 32 hours after initial conditions with initial waste temperature $=43^{\circ} \mathrm{C}$ and ambient temperature $=27^{\circ} \mathrm{C}$ (65\%-filled drum). 


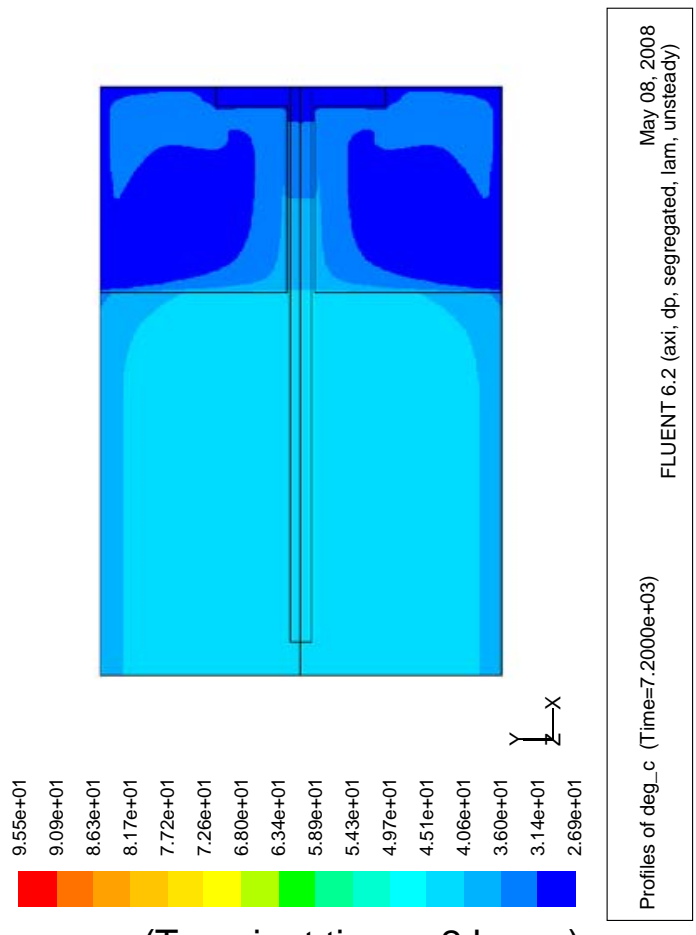

(Transient time $=2$ hours)

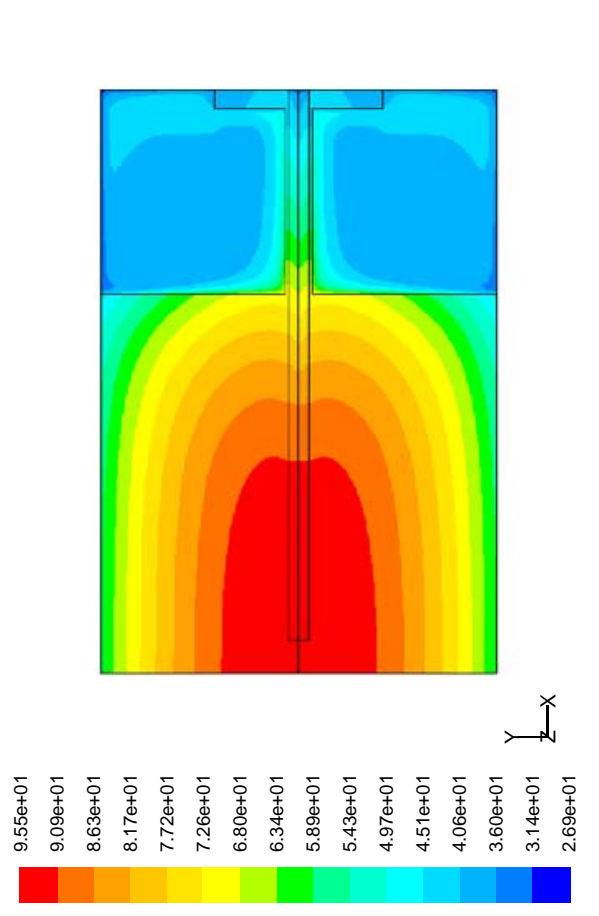

(Transient time $=32$ hours)

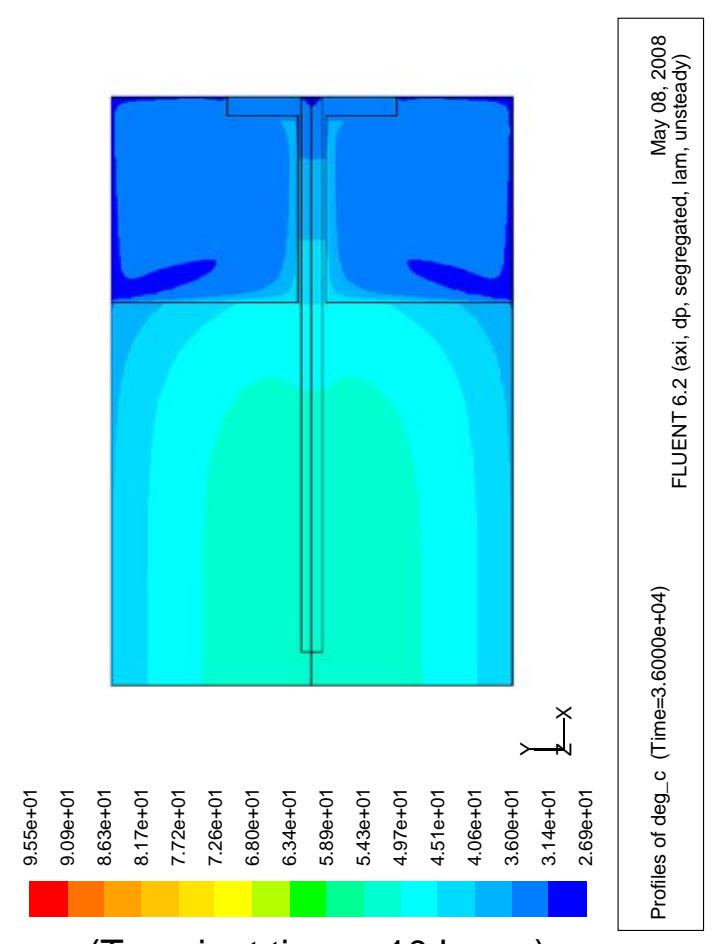

(Transient time $=10$ hours)

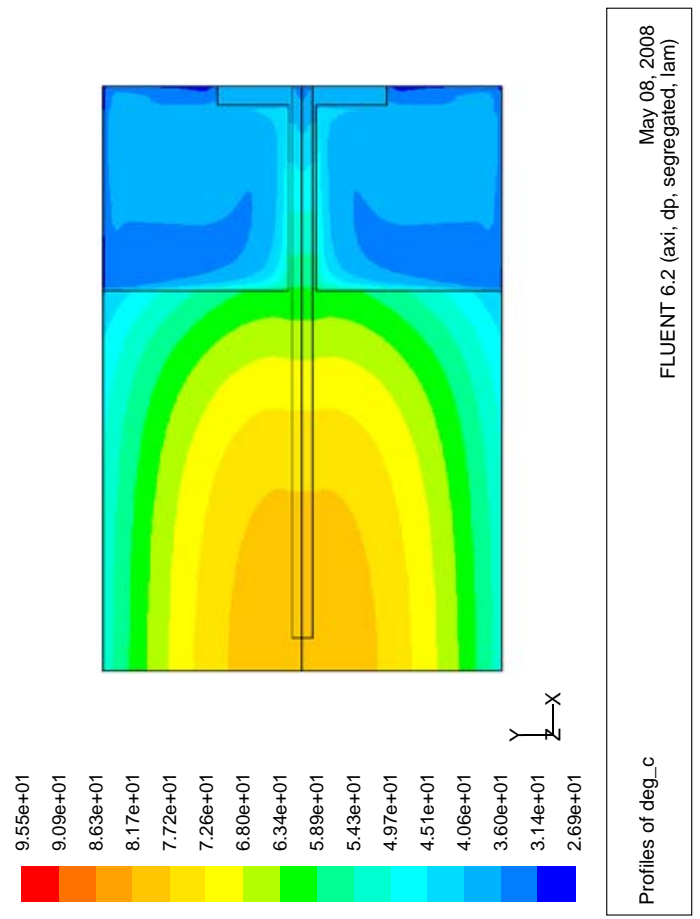

(Steady state based on the averaged heat source)

Figure 16. Transient snapshots of temperature distributions across the central plane of the 55-gallon drum with 65\%-filled waste form for initial waste temperature $=$ $43^{\circ} \mathrm{C}$ and ambient temperature $=27^{\circ} \mathrm{C}$ (As color code, red color is indicated as $95.46^{\circ} \mathrm{C}$, blue one is $26.85^{\circ} \mathrm{C}$ ). 


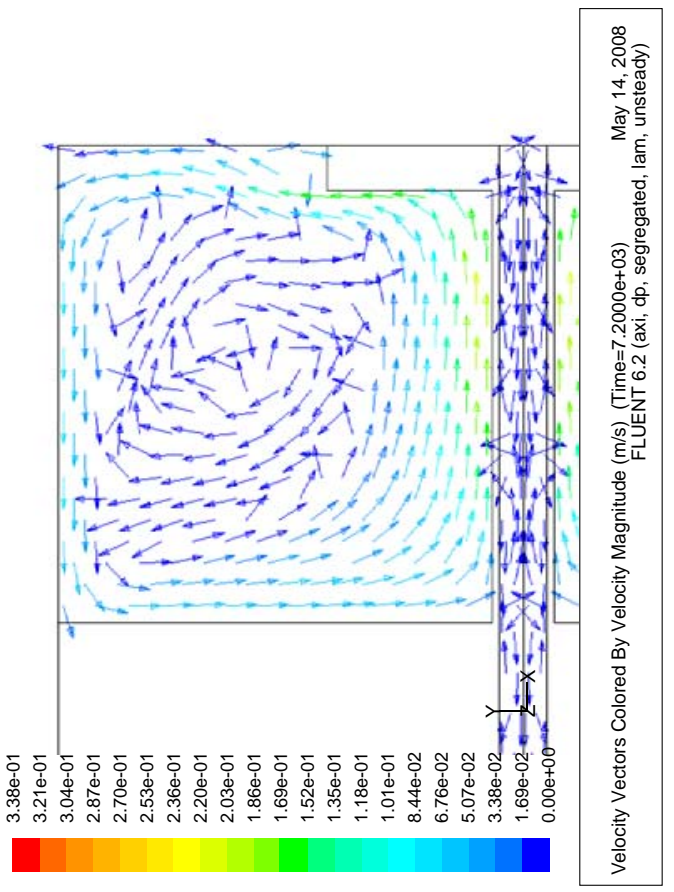

(Transient time $=2$ hours)

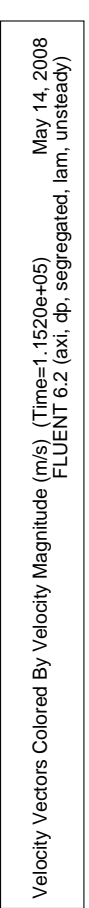

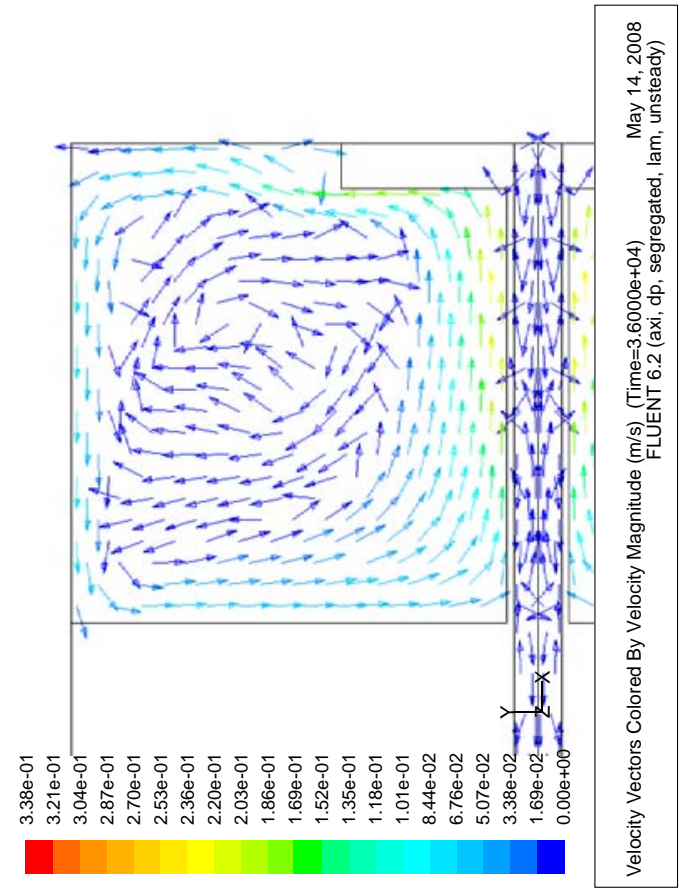

(Transient time $=10$ hours)

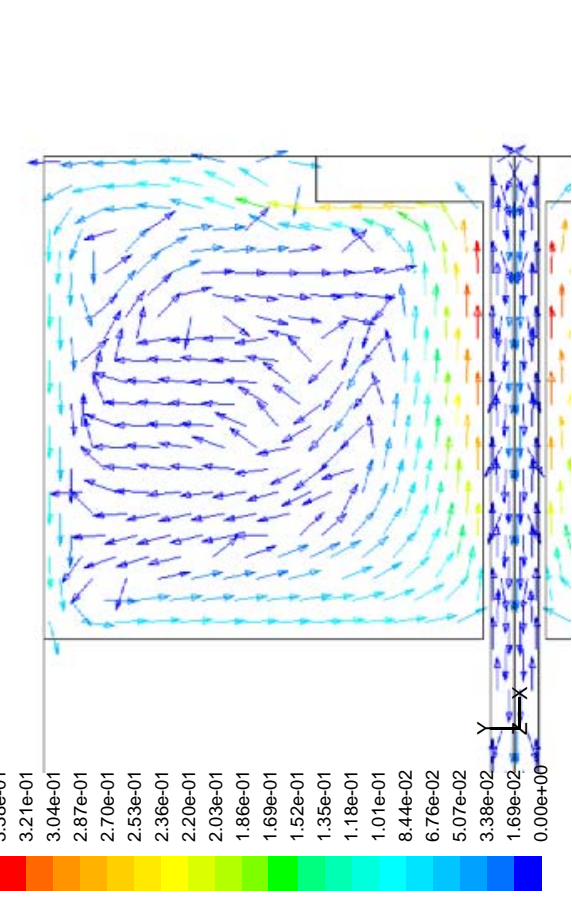

(Transient time $=32$ hours)

(Steady state based on the averaged heat source)

Figure 17. Transient snapshots of flow patterns for the enclosed gas region above the top surface of the cemented waste form inside the 55-gallon drum with $65 \%$ filled waste form for initial waste temperature $=43^{\circ} \mathrm{C}$ and ambient temperature $=27^{\circ} \mathrm{C}$ (As color code, red color is indicated as $0.338 \mathrm{~m} / \mathrm{sec}$, blue one is $0 \mathrm{~m} / \mathrm{sec}$ ). 


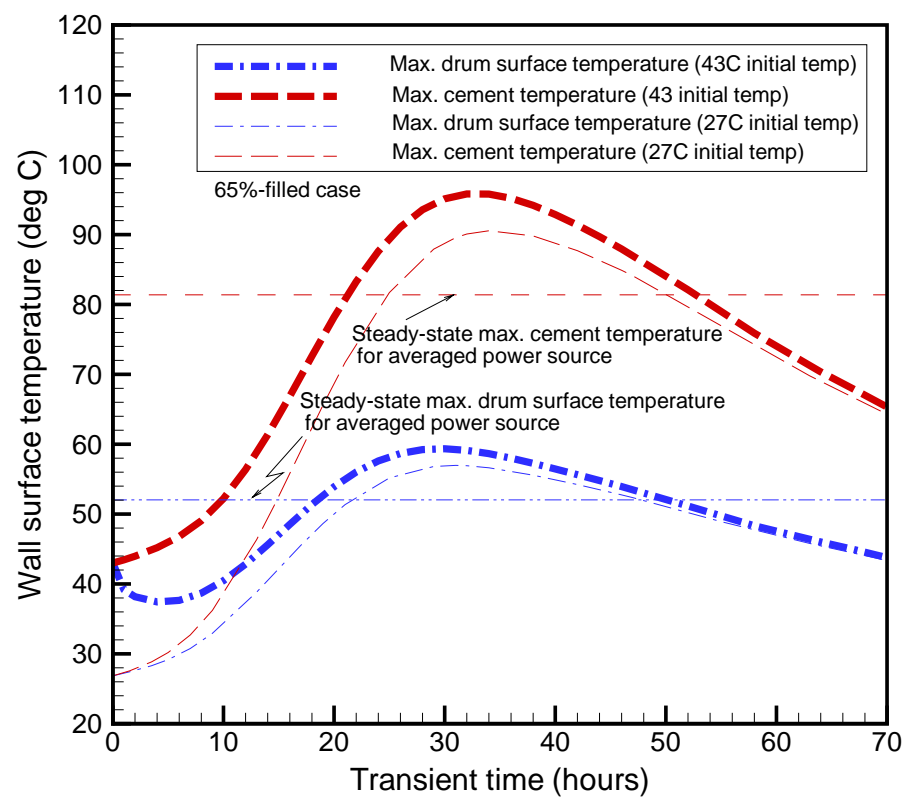

Figure 18. Comparison of transient maximum drum surface and waste temperatures between two different initial waste temperatures for the transient heat source provided by Fig. 2.

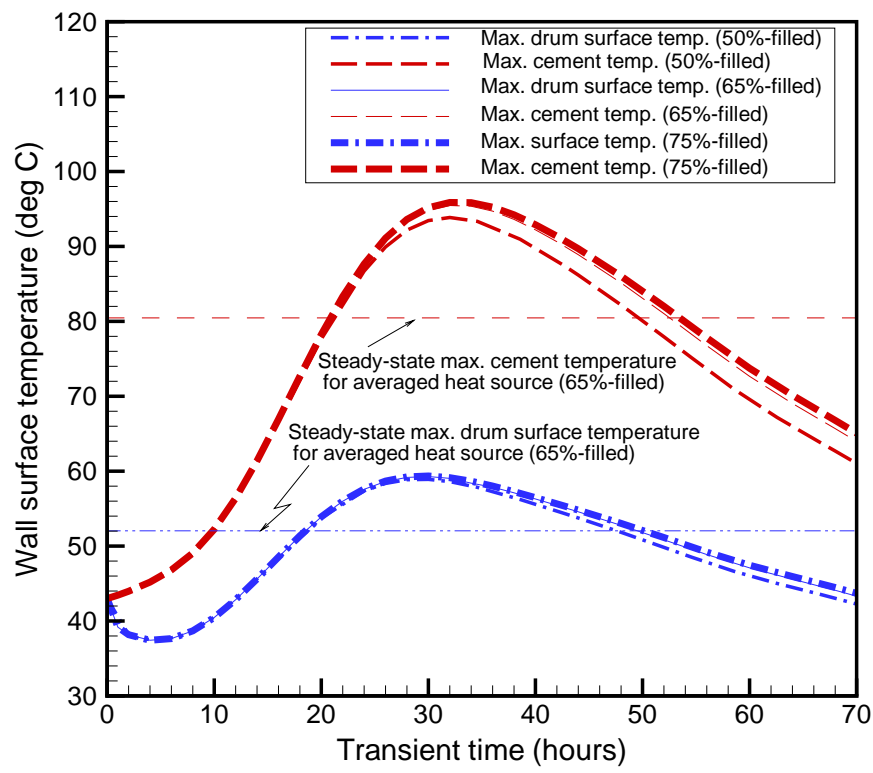

Figure 19. Comparisons of transient maximum drum surface and cement waste temperatures for different loadings of cement waste in a drum container (Initial waste temperature $=43^{\circ} \mathrm{C}$ and ambient temperature $=27^{\circ} \mathrm{C}$ ). 

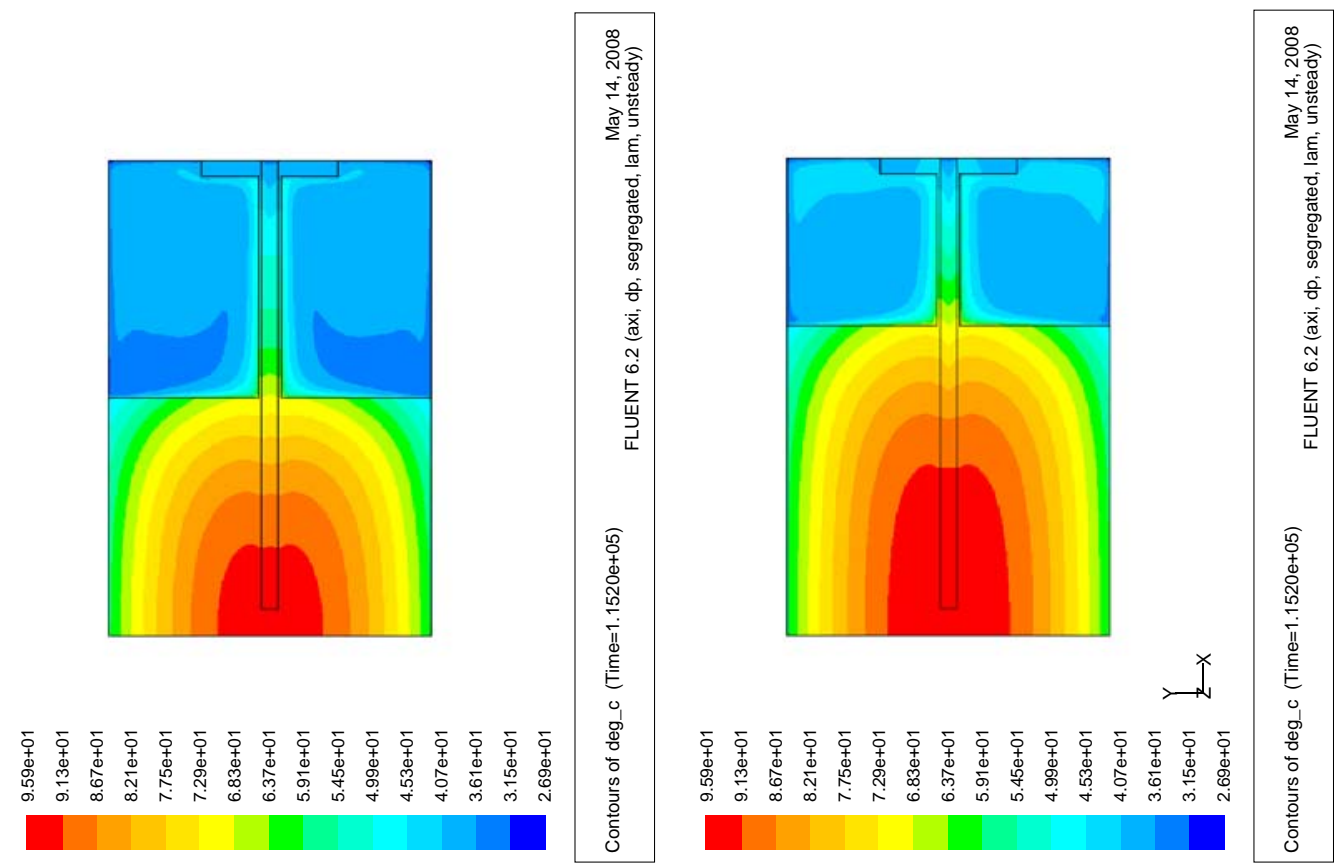

(50-\%-filled drum: $\mathrm{T}_{\max }=94.0^{\circ} \mathrm{C}$ )

(65\%-filled drum: $\left.\mathrm{T}_{\max }=95.5^{\circ} \mathrm{C}\right)$

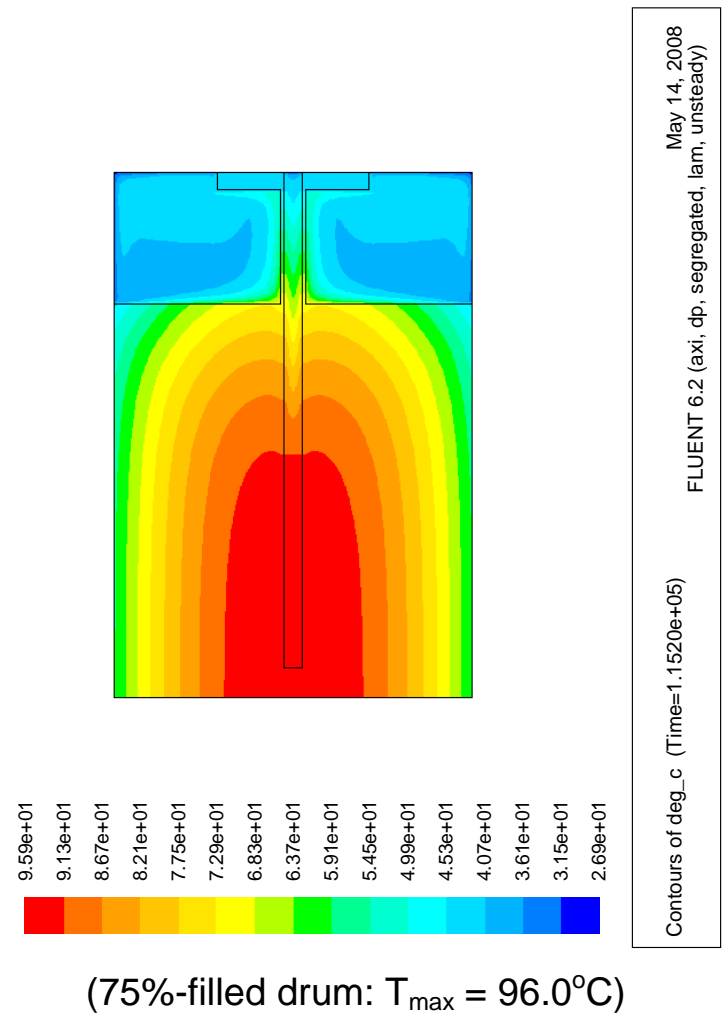

Figure 20. Comparison of temperature distributions cooled by natural convection at 32hour transient time for different sizes of gas enclosures above the top surface of the waste form cement region due to the different loading volumes of the cement waste form (As color code, red has temperature higher than $96.0^{\circ} \mathrm{C}$, and blue one has $26.85^{\circ} \mathrm{C}$.) 


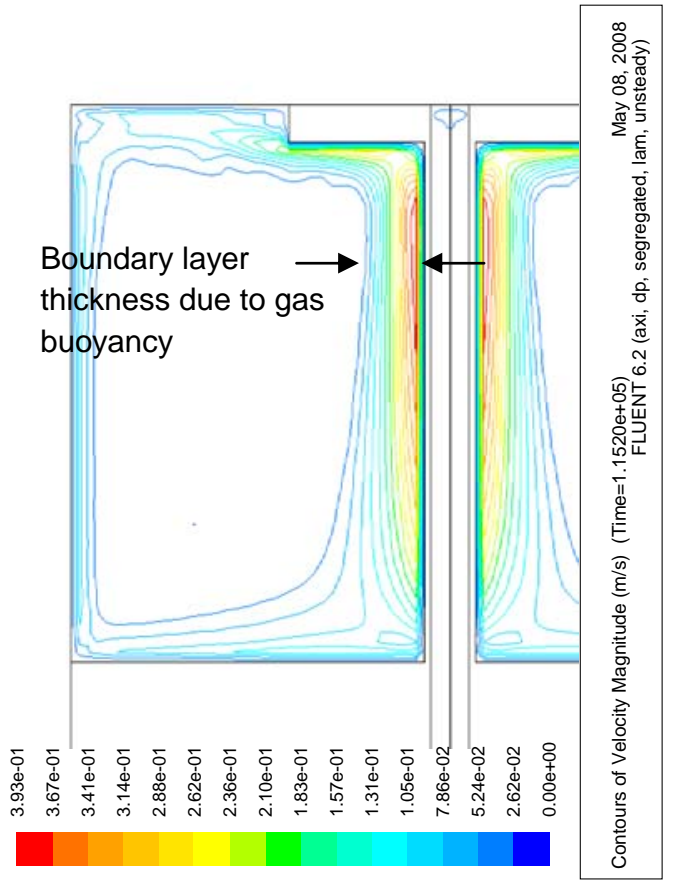

(50-\%-filled drum)

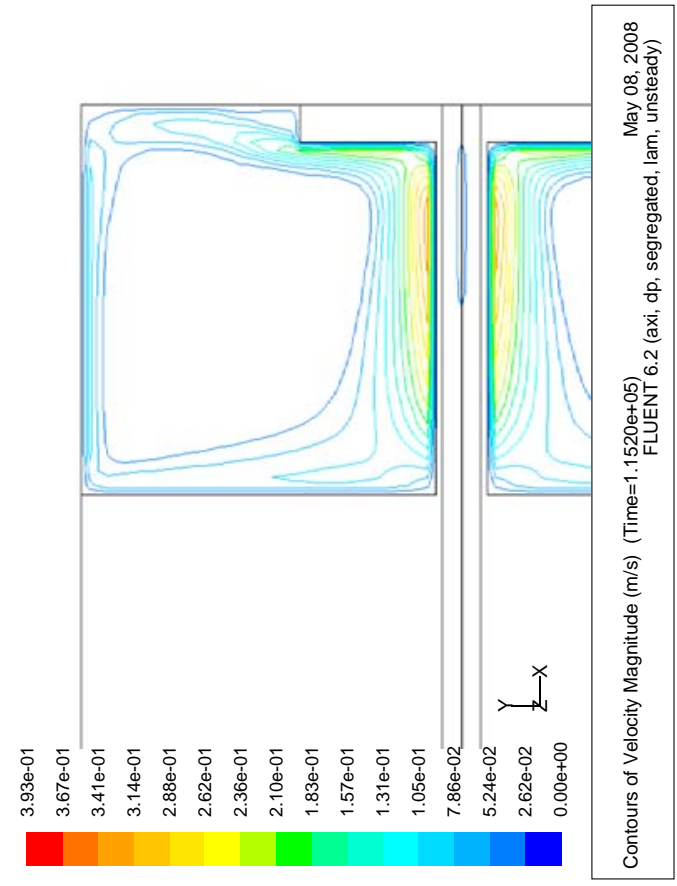

(65\%-filled drum)

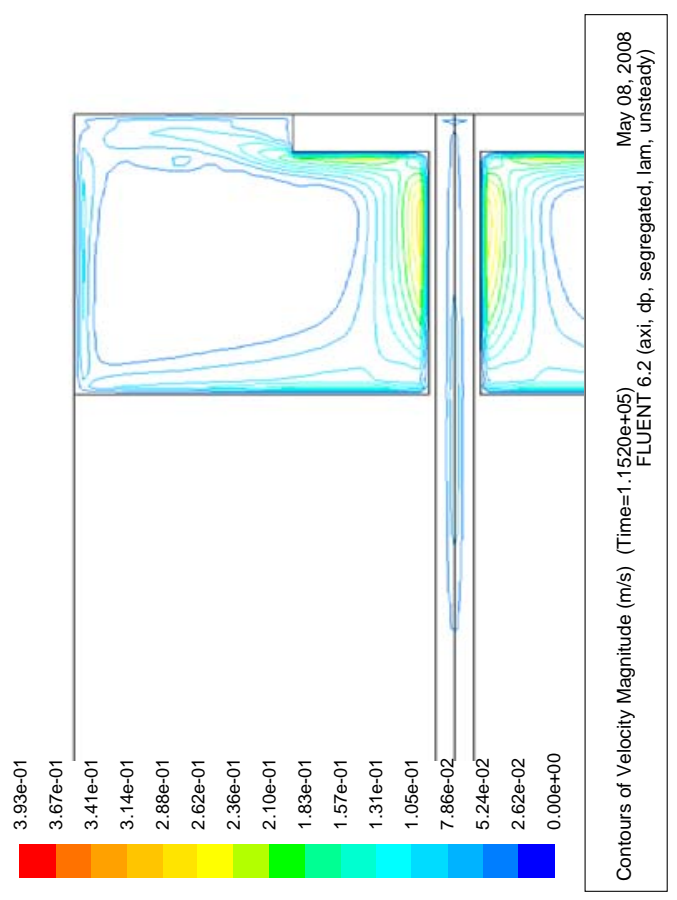

(75\%-filled drum)

Figure 21. Comparison of gas velocity flow patterns driven by natural convection at 32hour transient time for different sizes of gas enclosures above the top surface of the waste form cement region due to the different loading volume of the cement waste form (As color code, red has velocity higher than $0.39 \mathrm{~m} / \mathrm{sec}$, and blue one has zero velocity.) 
Page: $\quad 34$ of 38

Table 8. Comparison of convection to conduction cooling ratios for different height $(\mathrm{H})$ of the air enclosure above the cement waste form with the same heat loading at 32 hours of transient time during WSB drum storage

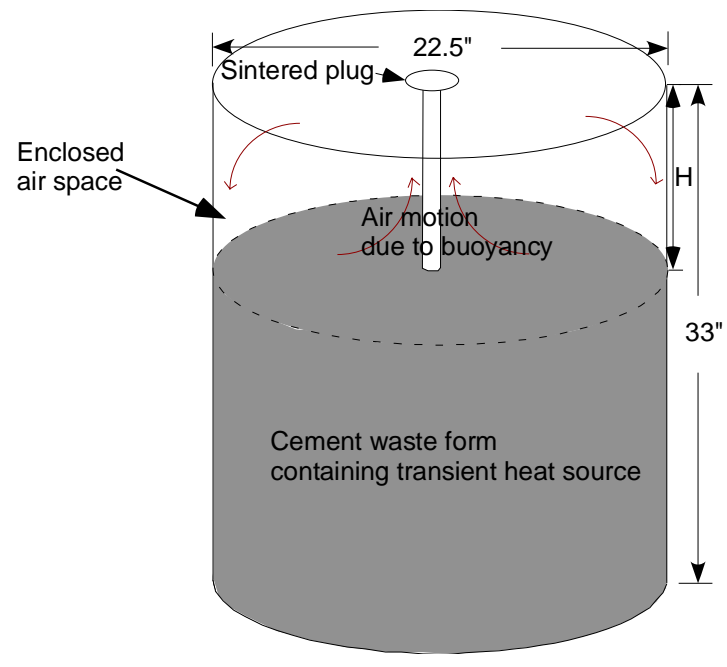

\begin{tabular}{|c|c|c|c|}
\hline Cases & $\begin{array}{c}\text { Height of gas region } \\
\text { above the cement } \\
\text { region } \mathbf{( H )}\end{array}$ & $\begin{array}{c}\text { Ratio of convection to } \\
\text { conduction cooling at the top } \\
\text { surface of cement region }\end{array}$ & $\begin{array}{c}\text { Peak temperature } \\
\text { of cement region } \\
\left({ }^{\circ} \mathrm{C}\right)\end{array}$ \\
\hline $\begin{array}{c}\text { Case 1 } \\
(65 \% \text {-filled drum) }\end{array}$ & 11.55 in & 83 & 95.5 \\
\hline $\begin{array}{c}\text { Case 2 } \\
(75 \% \text {-filled drum) }\end{array}$ & 8.25 in & 78 & 96.0 \\
\hline $\begin{array}{c}\text { Case 3 } \\
(50 \% \text {-filled drum) }\end{array}$ & 16.5 in & 90 & 94.0 \\
\hline
\end{tabular}

Table 9. Maximum surface and cement temperatures during the transient period of drum storage in a WSB facility

\begin{tabular}{|c|c|c|}
\hline \multirow{2}{*}{ Cases } & \multicolumn{2}{|c|}{ Max. temperature } \\
\cline { 2 - 3 } & Drum surface $\left({ }^{\circ} \mathrm{C}\right)$ & Cement region $\left({ }^{\circ} \mathrm{C}\right)$ \\
\hline $\begin{array}{c}\text { Case } 1 \\
(65 \% \text {-filled drum })\end{array}$ & 59.0 & 95.5 \\
\hline $\begin{array}{c}\text { Case 2 } \\
(75 \% \text {-filled drum })\end{array}$ & 59.1 & 96.0 \\
\hline $\begin{array}{c}\text { Case 3 } \\
(50 \% \text {-filled drum })\end{array}$ & 58.6 & 94.0 \\
\hline
\end{tabular}




\section{Conclusions}

Transient axi-symmetric two-dimensional heat transfer calculations have been performed to assess the thermal performance of the 55-gallon WSB drum container containing hydration heat source associated with the current cement waste form.

A series of the modeling calculations has been performed using a computational heat transfer approach, assuming that the cement waste form with transient heat source is cooled by natural convection of $27^{\circ} \mathrm{C}$ external air as a primary heat transfer mechanism. For Case 1, 65 percent of the drum volume was assumed to be filled with the waste form to determine the maximum drum surface and cement waste temperatures as the baseline loading condition. For Case 2, transient calculations under the maximum loading conditions of 75 percent filled drum were evaluated to investigate how sensitive the maximum waste and drum temperatures are to the loading volumes of the cement waste form. Case 3 quantified the transient thermal response to the lowest loading conditions of the cement waste form. In addition, the results computed by the present model were verified by the theoretical results.

From the present modeling results, the main conclusions are:

- The baseline modeling results show that transit times to reach maximum temperature of the $65 \%$-filled drum are about 32 hours when the $43^{\circ} \mathrm{C}$ initial cement temperature is cooled by natural convection of $27^{\circ} \mathrm{C}$ ambient air. In this case, maximum cement and maximum drum surface temperatures are $95.5^{\circ} \mathrm{C}$ and $59.0^{\circ} \mathrm{C}$, respectively.

- When the loading volume increases from 50 vol\% to 75 vol\% for the enclosed drum with initial cement temperature $43^{\circ} \mathrm{C}$ and ambient temperature $27^{\circ} \mathrm{C}$, the peak temperature over the entire drum increases about $2^{\circ} \mathrm{C}$ for the cement region and about $0.5^{\circ} \mathrm{C}$ for the external surface of the drum package.

- It is shown that peak temperature of the WSB drum containing heat source is reached at about 32 hours due to the low thermal diffusivity of the cement waste although hydration heat loading is peak at about 17.5 hours since the beginning of the cementation process.

- The results demonstrate that the buoyancy-driven gas circulation in the enclosed region above the cement region provides the primary cooling mechanism in reducing the peak drum temperature as shown in Table 8.

- The results show that increasing the cement volume from $50 \%$ to $75 \%$ does not greatly impact the maximum drum temperature or the heat rate.

- It is noted that the central stainless steel pipe (about 1.52 in diameter) clearly provides an effective conduction path in dissipating the hydration heat from the cement region containing heat source to the cooler ambient environment.

The modeling results will be benchmarked against the prototypic test results when the test data are available. The verified model will be used for the evaluation of the thermal performance for the WSB drum. 


\section{$5 \quad$ References}

1. A. D. Cozzi, E. K. Hansen, and D. J. Pak, "SRNL Support for the Waste Solidification Building", WSRC-TR-2008-00067, Rev. 0, March 2008.

2. A. D. Cozzi, E. K. Hansen, and J. R. Harbour, "Heat of Hydration Testing For WSB HAW Waste Form", Inter-Office Memorandum, SRNL-PSE-2007-00281, December 2007.

3. FLUENT, Fluent, Inc., 2006.

4. S. Y. Lee, "Heat Transfer Analysis for Fixed CST and RF Column", WSRC-STI2007-00345, October 2007.

5. C. Y. Warner and V. S. Arpaci, "An Experimental Investigation of Turbulent Natural Convection in Air at Low Pressure along a Vertical Heated Flat Plate", International Journal of Heat and Mass Transfer, Vol. 11, pp. 397-406 (1968).

6. J. P. Perry, Chemical Engineers' Handbook, $3^{\text {rd }}$ edition, McGraw-Hill Book Company, Inc., 1950.

7. J. P. Holman, Heat Transfer, $4^{\text {th }}$ edition, McGraw-Hill Book Company, New York (1976).

8. WSB Cementation Mixing System Project, DWG-5527-ME-4000-1, Rev. A, February 2008.

9. Kays, W. M. and Crawford, M. E., 1980. Convective Heat and Mass Transfer, Second Edition, McGraw-Hill Book Company. 


\title{
Attachment:
}

\section{E-Mail Correspondence on Material and Thermal Properties}

Alex Cozzi/SRNL/Srs

04/04/2008 09:06 AM

\author{
To Si Lee/SRNL/Srs@Srs \\ cc Steve Hensel/SRNL/Srs@Srs, David Crowley/SRNL/Srs
}

\section{Subject Fw: Waste Solidification Building modeling \\ Si Young,}

Here is the info you requested - and more. Not all of it directly applies to the specific mix, as the formulation has changed some.

Current formulation (by mass) for one 55 gallon stainless steel drum filled to $65 \%$ capacity

\section{water to cement ratio 0.3}

cement to $\mathrm{ZrSiO} 4$ ratio $12: 1$

$162.3 \mathrm{~kg}$ cement (type II) density $3.14 \mathrm{~g} / \mathrm{ml}$

$13.5 \mathrm{~kg} \mathrm{ZrSiO} 4$ density $4.79 \mathrm{~g} / \mathrm{ml}$

$77.4 \mathrm{~kg}$ salt solution density $1.29 \mathrm{~g} / \mathrm{ml} 61.8 \mathrm{wt} \%$ water

Density of the waste form $-2.2 \mathrm{~g} / \mathrm{mL}$

\section{from literature}

specific heat of the waste form (estimated by cement paste) $-=0.736 \mathrm{~J} / \mathrm{g} \mathrm{K}$

thermal conductivity of the waste form (estimated by cement paste) $-=0.53 \mathrm{~W} / \mathrm{m} \mathrm{K}$

Heat generation term is in the attached excel spreadsheet. It was modeled by Tommy Edwards using the JMP Neural Network to fit the curve measured by isothermal calorimetry @ $25^{\circ} \mathrm{C}$. The data was generated from a single specimen and, at the time, the formulation used $\mathrm{ZrO} 2$ at a cement to ZrO2 ratio 2:1. Also attached is the memo describing the collection of this data.

I will be out next week, but I anticipate having access to my e-mail.

Alex Cozzi, Ph.D.

Savannah River National Laboratory

(803) 819-8414

pager (803) 7257243

16878

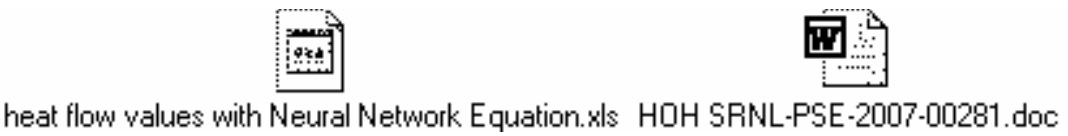


Page: $\quad 38$ of 38

\title{
2. E-Mail Correspondence on 55-gallon WSB Drum Dimensions
}

\section{Alex Cozzi/SRNL/Srs}

04/16/2008 08:32 AM

\author{
To Si Lee/SRNL/Srs@Srs \\ cc David Crowley/SRNL/Srs
}

Subject drum dimensions

Si Young,

The stainless drums in stores have dimensions of $\mathrm{D}=22.5^{\mathrm{N}} \mathrm{H}=33$ " so the volume is $\sim 56.8 \mathrm{gal}$. The drums are site stores purchased using the attached specs.

Alex Cozzi, Ph.D.

Savannah River National Laboratory

(803) 819-8414

pager (803) 7257243

16878

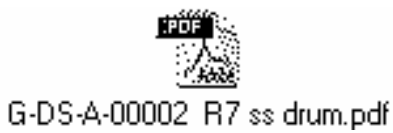

